\title{
Review of Reactions and Molecular Mechanisms in Cellulose Pyrolysis
}

$\operatorname{AUTHOR}(\mathrm{S}):$

Kawamoto, Haruo

CITATION:

Kawamoto, Haruo. Review of Reactions and Molecular Mechanisms in Cellulose Pyrolysis. Current Organic Chemistry 2016, 20(23): 2444-2457

ISSUE DATE:

2016-05-25

URL:

http://hdl.handle.net/2433/240620

\section{RIGHT:}

This is the ACCEPTED VERSION of the peer-reviewed article. The published manuscript is available at EurekaSelect via http://www.eurekaselect.com/142480; The full-text file will be made open to the public on 25 May 2017 in accordance with publisher's 'Terms and Conditions for Self-Archiving'.; This is not the published version. Please cite only the published version.; この論文は出版社版でありません。引用の際には出版社版をご確認ご利用ください。 


\title{
Review of Reactions and Molecular Mechanisms in Cellulose Pyrolysis
}

\author{
Haruo Kawamoto \\ Department of Socio-Environmental Energy Science, Graduate School of Energy Science, Kyoto \\ University, Yoshida-Honmachi, Sakyo-Ku, Kyoto 606-8501, Japan
}

\begin{abstract}
Cellulose, which is a polymer of $\beta-1 \rightarrow 4$ linked D-glucose units, comprises about half the components of lignocellulosic biomasses. A better understanding of the chemistry involved in cellulose pyrolysis provides valuable insights into the development of efficient pyrolysis-based conversion technologies of biomass into biofuels, biochemicals and biomaterials. This review focuses on the reactions and molecular mechanisms that determine the reactivity and product selectivity in pyrolysis and the related conversion technologies. This information is useful for understanding the processing technologies conducted at high temperatures, such as wood drying and the production of cellulose-plastic composite materials. Because the cellulose pyrolysis behavior changes drastically in the temperature range of $300-350{ }^{\circ} \mathrm{C}$, this review is divided into low- and high-temperature regimes. The intermediates produced from cellulose pyrolysis are further converted into various gas, liquid or solid products. Hence, these processes are addressed as primary pyrolysis and secondary reactions in this review. The roles of the crystalline cellulose in pyrolysis are noted.
\end{abstract}

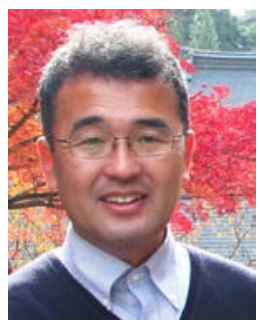

Keywords: Cellulose, pyrolysis, gasification, carbonization, molecular mechanism, controlled pyrolysis, hydrogen bond theory.

\section{INTRODUCTION}

Cellulose is a crystalline polymer consisting of $\beta-1 \rightarrow 4$ linked D-glucose units and comprises about half of the components of lignocellulosic biomasses. Together with the massive amount of lignocellulosic biomass produced and accumulated on the earth, cellulose is the most important bioresource, and can be utilized as renewable materials and for the production of biofuels and biochemicals. The pyrolysis-based technologies, which include gasification, fast pyrolysis, carbonization and torrefaction, are promising for this purpose.

Understanding the molecular mechanisms involved in the pyrolysis of lignocellulosic biomass is helpful to improve pyrolysis-based technologies, although these are prone to be treated as "black boxes". Cellulose is the most widely studied lignocellulosic in the pyrolysis field. Hence, there are many excellent reviews concerning cellulose pyrolysis [1-6]. However, the reactions and molecular mechanisms involved in cellulose pyrolysis have received little focus. They are the main context of the present review, which was previously published in Japanese [7].

The present review does not include the following topics regarding cellulose pyrolysis, kinetic treatment on the massloss behavior and conversion technologies to

*Address correspondence to this author at the Department of SocioEnvironmental Energy Science, Graduate School of Energy Science, Kyoto University, Yoshida-Honmachi, Sakyo-Ku, Kyoto 606-8501, Japan; Tel: +81-75-753-4737; $\quad$ Fax: +81-75-753-4737; $\quad$ E-mail: kawamoto@energy.kyoto-u.ac.jp biofuels/biochemicals. The reactions proceeding in hotcompressed water including supercritical conditions are excluded, because these are closely related to hydrolysis reactions. The studies of the theoretical calculations for specific pyrolysis reactions of cellulose and related model compounds are also excluded in this review.

Cellulose pyrolysis is believed to proceed in two stages, the volatile and non-volatile intermediates formed by the thermal degradation of cellulose, and the degradation into the final products including gas, liquid (tar and wood vinegar or pyroligneous acid) and solid (char and coke) products. Thus, these processes are treated in this review as primary pyrolysis and secondary reactions, although a strict distinction between them is not always easy.

The primary pyrolysis stage can be divided into two regimes depending on the pyrolysis temperature, as summarized in the previous reviews authored by Shafizadeh [1] and Antal [2]. Two competitive pathways are believed to be involved in cellulose pyrolysis [1,2,8,9]. One is the pathway to form char along with water and gaseous products at relatively low temperatures $<300{ }^{\circ} \mathrm{C}$, and the other pathway produces volatile products selectively at higher temperatures. This idea was proposed by Kilzer and Broido [8], and many kinetic investigations have been conducted with these pathways.

\section{TEMPERATURE OF CELLULOSE PYROLYSIS}


The temperature ranges where cellulose pyrolysis occurs have been studied by thermogravimetric analysis (TGA). These data provide the information for the slow pyrolysis conducted at relatively low heating rates. Cellulose starts to decrease in weight around $300{ }^{\circ} \mathrm{C}$ with a standard heating rate of $10^{\circ} \mathrm{C} / \mathrm{min}$ under nitrogen flow, and the mass loss attains a maximum around $350{ }^{\circ} \mathrm{C}$, which can be easily observed in the derivative TG (DTG) curve. The DTG peak temperature shifts to higher temperatures when using higher heating rates. However, this shift can be explained by the response lag in the temperature measurement and the heat of evaporation for the volatile products [10-14].

Crystalline cellulose exhibits a DTG peak at temperatures higher than that of ball-milled [15-17] or ammonia-swollen [18] non-crystalline cellulose. Thus, the mass loss rate increases directly with an increase in the content of the noncrystalline region [19]. The higher reactivity of the noncrystalline cellulose is confirmed with the disappearance of hydroxyl groups in the non-crystalline region of cellulose as indicated by the hydrogen-deuterium exchange method [20]. Simple glycosides with relatively low melting points melt and decompose in the temperature range lower than that of cellulose pyrolysis [21,22]. The size of the crystallites in cellulose, which is greater in the order of Halocynthia $\left(389{ }^{\circ} \mathrm{C}\right)>\operatorname{cotton}\left(366{ }^{\circ} \mathrm{C}\right)>$ microcrystalline cellulose $\left(34{ }^{\circ} \mathrm{C}\right.$ ), is reported to affect the DTG peak temperature (value in the parenthesis is the DTG peak temperature) [23]. The stability of cellulose against heat relies on its crystalline nature.

Fibrillation by a homogenizer reduces the thermal stability of cellulose. The DTG peak temperature decreases from around 360 to $300{ }^{\circ} \mathrm{C}$ along with the appearance of a shoulder at $250{ }^{\circ} \mathrm{C}$, where the major product, water, is formed through dehydration reactions [24].

Although cellulose is converted into char that maintains the original shape, but reduces in size under slow heating conditions, cellulose is completely converted into molten intermediates under fast pyrolysis conditions with very high heating rates [25-31]. These fast conditions, which can be accomplished with a radiation flash pyrolysis or an ablative pyrolysis, are promising for bio-oil production from biomass. The volatilization process via the molten intermediates can be visualized using a high-speed camera $[27,28]$.

The research group of Lédé extensively studied the formation and devolatilization of the molten intermediates during the fast pyrolysis of cellulose and reported that the temperature of the intermediates during the steady state of pyrolysis is $466{ }^{\circ} \mathrm{C}$ [29]. Their group also estimated the lifetime (less than $1 \mathrm{~s}$ ) [30] and the formation temperature $\left(443{ }^{\circ} \mathrm{C}\right)$ for the molten intermediates [31]. Shoji et al. [32] directly measured the temperature of cellulose during pyrolysis. A small amount of cellulose sample with a thermocouple is plunged into the furnace under nitrogen flow (Figure 1). The plateaus observed in the temperature profiles, which arise from the evaporation of the volatile products formed by the cellulose decomposition, shift from $360-380$ to $400-450{ }^{\circ} \mathrm{C}$ by increasing the furnace temperature. These results suggest that the cellulose decomposition for fast pyrolysis conditions occurs around $400-450{ }^{\circ} \mathrm{C}$, the temperature range is much higher than the $350{ }^{\circ} \mathrm{C}$ observed for slow pyrolysis conditions measured by TGA.

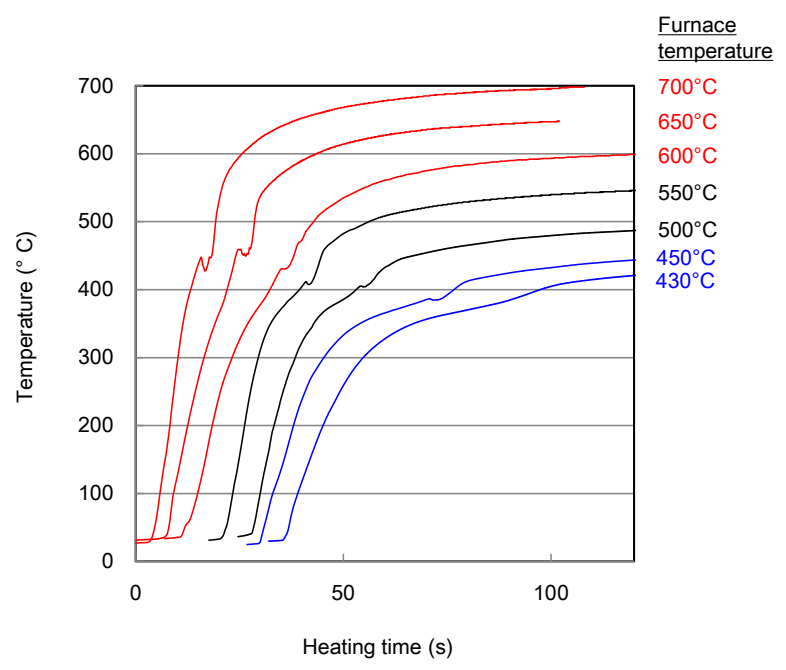

Fig. (1). Temperature profiles from the in situ measurement of cellulose (Avicel PH-101), when a small amount of cellulose in a ceramic boat was plunged into the furnace preheated at various temperatures under nitrogen flow [32].

Other than thermal reactions for cellulose depolymerization, two processes, devolatilization and char formation, which have opposite effects, affect the decomposition temperature of cellulose during pyrolysis. Devolatilization is an endothermic process and tends to decrease the cellulose temperature, which causes plateauing of the sample temperature [10-12,31] as observed in Figure 1. Milosavljevic et al. [33] estimated the heat demand for the devolatilization process as $538 \mathrm{~J} / \mathrm{g}$ (volatiles). However, the formation of solid carbonized materials (char) is a strong exothermic process, which is estimated as $2 \mathrm{~kJ} / \mathrm{g}$ (char) [33]. Consequently, the decomposition temperature of cellulose in a steady state of pyrolysis varies depending on the balance of these processes [33,34].

\section{PRIMARY PYROLYSIS REACTIONS}

\subsection{Low-Temperature Regime $\left(<300{ }^{\circ} \mathrm{C}\right)$}

At temperatures $<300{ }^{\circ} \mathrm{C}$, cellulose decomposition is slow, but some structural alternations occur, which include reducing and plateauing of the degree of polymerization (DP), crystallization and thermal decomposition of reducing end (RE) groups and molecules in the non-crystalline regions.

\subsubsection{Reducing the Degree of Polymerization}

The DP of cellulose decreases to a plateau (around 200) under acid-catalyzed hydrolysis conditions. Similar DP reduction occurs during pyrolysis $<300{ }^{\circ} \mathrm{C}$, even at temperatures as low as $150-200{ }^{\circ} \mathrm{C}$ [20,35-42]. This process is accelerated in the presence of oxygen [35].

Matsuoka et al. [41] reported that RE groups were formed during this DP reduction until a plateau is reached from oven-dried cellulose. This conversion requires water, such as adsorbed water and that produced from the decomposition of REs.

Although this DP reduction is the initial reaction of cellulose during pyrolysis, the literature dealing with the mechanism is limited. Broido et al. [39] reported that the DP of Whatman cellulose decreased from 2650 to 200-400 in the temperature range of $175-225{ }^{\circ} \mathrm{C}$, whereas the 
amorphous cellulose prepared from the ammonia-swollen cellulose exhibited a continuous DP reduction followed by crystallization. From these results, they proposed a mechanism. The DP reduction occurs at the interface of crystalline and non-crystalline regions of cellulose, where the strain is maximized. The size of cellulose crystallite is consistent with this DP plateau, which supports the proposal.

\subsubsection{Dehydration and Role of Cellulose Reducing Ends}

The van Kreveren diagram, which is a graphical plot of $\mathrm{H} / \mathrm{C}$ versus $\mathrm{O} / \mathrm{C}$ of the char fractions, is effective to study the reactions occurring during the pyrolysis of cellulose. Tang and Bacon [43] concluded that the major pyrolysis reaction in the temperature range of $200-280^{\circ} \mathrm{C}$ is dehydration. The formation of a significant amount of water is also reported in this temperature range [44-46].

For converting cellulose to stiff materials, a mechanism based on crosslinking cellulose molecules through the formation of the ether linkages between two $\mathrm{C}-\mathrm{OH}$ groups has been proposed [8,47]. However, no concrete experimental support has been reported for this mechanism. Direct etherification is not probable, because simple alcohols such as glycerol are stable at these temperatures.

Matsuoka et al. showed that cellulose REs are more reactive compared with the other parts of cellulose molecules, because cellulose is stabilized against thermal decomposition and discoloration by the elimination of its REs through glycosylation with glycerol [48] or reduction with $\mathrm{NaBH}_{4}$ [42]. Thus, the cellulose RE is expected to be a reactive site in the low temperature region.

The reactivity of the RE is indicated by the reactivities of simple reducing sugars, which are much greater than those of the non-reducing sugars for thermal polymerization and discoloration [49-54]. For example, glucose, a monomeric reducing sugar, forms polysaccharides at $150{ }^{\circ} \mathrm{C}$ (melting point of glucose) by releasing water through transglycosylation reactions following the melting process [50]. However, the pyrolytic reactions of monomeric glycosides such as methyl glucoside start at a higher temperature of $250-300{ }^{\circ} \mathrm{C}[21,22]$. As for disaccharides, Shafizadeh and Lai [53] reported that cellobiose with an RE became reactive at $250{ }^{\circ} \mathrm{C}$ for thermal polymerization, whereas trehaose with no RE was stable up to around $300{ }^{\circ} \mathrm{C}$, which is a temperature much higher than the melting point $\left(215^{\circ} \mathrm{C}\right)$. Although it is unclear why reducing sugars are more reactive than non-reducing sugars for thermal polymerization (transglycosylation), crosslinking through the glycosylation at the REs can be considered during the low temperature pyrolysis of cellulose, which also produces water.

Thermal polymerization is the first event during the pyrolysis of reducing and non-reducing sugars, which produces polysaccharides (see Section 4.3.). Consequently, even simple monosugars including glucose are not directly decomposed into smaller molecules except for the water formed during polymerization, but via the molten state of polysaccharide intermediates.

The reactivity of the REs of cellulose (Avicel PH-101) for thermal glycosylation has been studied using glycerol as a model alcohol, which can penetrate into the space between cellulose crystallites. The thermal glycosylation reactivity varies depending on the pyrolysis temperature [48]. About $20 \%$ of REs, which corresponds to the non-crystalline region of cellulose, are glycosylated in the temperature range of $140-160{ }^{\circ} \mathrm{C}$ as observed for glucose. However, the glycosylation of the other $80 \%$ needs higher temperatures > 200-240 ${ }^{\circ} \mathrm{C}$, where the discoloration [55] and thermal expansion of cellulose I $\beta$ in the direction of the a-axis of the crystallite [56] start. Different reactivities may originate from the accessibility of glycerol to the crystallites of cellulose, which varies depending on the pyrolysis temperature.

In the absence of glycerol, only a small signal, which indicates the coupling of two cellulose molecules, are detected in the gel permeation chromatogram of heat-treated cellulose (as a phenyl carbamate derivative) [48]. From these results, the possibility of crosslinking through the glycosylation at the REs is limited, probably because of the restricted mobility of cellulose macromolecules in the crystallites. Under these conditions, the cellulose REs may decompose via other pathways, which include the dehydration via conjugated enol intermediates (see Section 3.2.2.) to form furanic intermediates. These decomposition reactions also produce water.

The research group of Antal [57,58] discovered an interesting phenomenon. The water in a closed system substantially reduces the DTG peak temperature, although water is not effective in a standard open-type sample holder. This finding was used to propose a mechanism. Water in a closed system causes hydrolysis reactions of cellulose as shown by reactions in supercritical water. Recently, Yu et al. [59] reported the formation of oligosaccharides up to a decamer, which have the RE groups, from Avicel PH-101. These amounts increase up to $270{ }^{\circ} \mathrm{C}$, and tend to convert into the corresponding anhydrosugars at higher temperatures. This finding indicates that hydrolysis reactions also proceed during the dry pyrolysis of cellulose. The space between crystallites is considered to act as quasi-closed environment (see Section 6). Matsuoka et al. [47] also indicate that this hydrolysis (transglycosylation) reaction is accelerated by the water formed through the thermal decomposition of cellulose REs, because of the reactivity of the $\mathrm{NaBH}_{4}$-reduced cellulose as well as the model experiments using cellulose impregnated with a simple methyl glucoside. Water formed in the space between crystallites may act as a key compound for thermal transglycosylation to proceed via reactive REs, which are continuously produced.

\subsection{High-Temperature Regime $\left(>300{ }^{\circ} \mathrm{C}\right)$}

Cellulose quickly decomposes in this temperature range to give volatile products along with char. The volatile products include anhydrosugars, furanic compounds and C1C3 fragments formed through depolymerization (transglycosylation), dehydration and fragmentation reactions, respectively.

The major components of the volatile products are shown in Figure 2. Levoglucosan (1,6-anhydro- $\beta$-D-glucopyranose, LG, 1) is the major monosugar produced from cellulose pyrolysis, along with the smaller contribution of the furanose derivative, 1,6-anhydro- $\beta$-D-glucofuranose (AF, 2). Anhydrosugars having additional intramolecular ether linkages such as 1,4:3,6-dianhydro- $\alpha$-D-glucopyranose (3) 
are also detected as minor components. Levoglucosenon (4) and $\gamma$-lactone (5) are also formed under the pyrolysis conditions including acidic catalysts.

Various furanic and pyranic compounds are produced via the dehydration reactions, which include furfural (6) and 5hydroxymethylfurfural (5-HMF, 7) as the important contributors. Hydroxybenzenes have also been reported.

Aldehydes [hydroxyacetaldehyde (HAA, 8), formaldehyde (9), acrolein (10) and glyoxal (11)], ketones [hydroxyacetone (12)] and acids [acetic acid (13) and formic acid (14)] are the major fragmentation products.
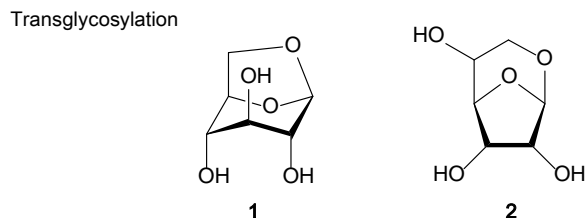

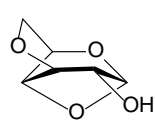

3

Dehydration
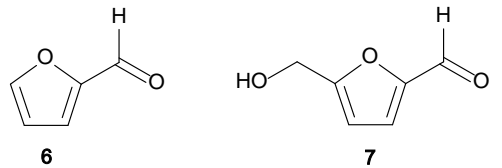

Fragmentation

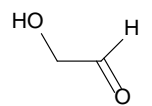

8

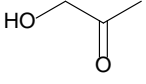

12

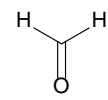

9

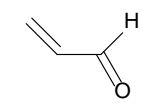

10

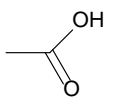

13

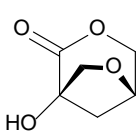

5
Fig. (2). Major volatile products from cellulose pyrolysis.

\subsubsection{Transglycosylation}

Large amounts (up to 60-70 wt\%) of LG form during the pyrolysis through the cleavage of the glycosidic bond of cellulose (transglycosylation) [60-62]. Thus, LG is considered an important pyrolysis intermediate. The first report of LG formation from cellulose was published by Pictet and Sarasin [63], and they indicated that LG polymerizes at $240{ }^{\circ} \mathrm{C}$, which is lower than the formation temperature [64]. These contradictory observations are discussed in Section 5. Anhydro-cellooligosaccharides are detected from cellulose under fast pyrolysis conditions [6569].

The inorganic contaminants of cellulose affect the formation of LG during pyrolysis. The cellulose samples having higher crystallinities produce more LG, and the inorganic substances contained in cellulose and other lignicelluosic samples drastically reduce the yield of LG, but increase the char yield $[60,64,70]$. Even neutral salts such as $\mathrm{NaCl}$ and $\mathrm{KCl}$ exhibit significant effects [71-74]. The molecular-based explanations are limited except for the following examples. Halpern and Patai [71] explained the influence of $\mathrm{NaCl}$ in cellulose by the action of $\mathrm{NaOH}$, which is formed via the thermal decomposition of $\mathrm{NaCl}$ followed by the removal of the $\mathrm{HCl}$ gas as a product through evaporation. Shimada et al. [75] proposed the role of Lewis acidity of $\mathrm{Mg}$ in $\mathrm{MgCl}_{2}$, which is active only under the dry conditions because of the extensive hydration in aqueous solutions. With the action of a Lewis acid, cellulose is hydrolyzed, which significantly decreases the DTG peak temperature of cellulose along with the yield of LG, but enhances char formation [76]. Because of the strong influence of inorganic substances, demineralization prior to pyrolysis improves the LG yield from cellulose pyrolysis $[60,64,70]$.

In wood pyrolysis, the metal cations such as $\mathrm{K}^{+}$and $\mathrm{Ca}^{2+}$, which are salts of uronic moieties in hemicellulose, affects the yields of anhydrosugars including LG [77-79]. Because most of the cations reduce the anhydrosugar yield, preneutralization of these cations with a strong acid such as sulfuric acid was reported to improve the LG yield from wood [80]. Conversely, the addition of some transition metal cations such as $\mathrm{Fe}$ and $\mathrm{Cu}$ is reported to improve the yield of LG [79], although the underlying mechanism is unknown.

The formation of AF, the furanose isomer of $\mathrm{LG}$, is low from the pyrolysis of cellulose, although the yield from reducing sugars such as glucose is high. Such differences have been discussed using reducing and non-reducing structures. The repeating glucose units of cellulose have pyranose rings. Hence, the formation of the products with furanose rings, which include AF and furanic compounds, requires the opening of pyranose rings. These conversions are possible at the $\mathrm{RE}$ groups via chain structures. Consequently, the LG/AF/furanic compounds ratio is strongly influenced by the DP of carbohydrates [81-85]. For example, Gardiner [81] reported that the yield of LG increases in the order of glucose $(17.0 \%)<$ cellobiose $(22.7 \%)<$ cellulose $(38.5 \%)$, whereas the AF yield decreased in this order $(10.9 \%>2.8 \%>1.5 \%)$. Kato [82] reported that the yield of furfural exhibits a similar trend to AF:glucose $(11.7 \%)>$ cellobiose $(7.7 \%)>$ cellulose (3.7\%).

Furthermore, the interconversion of LG $\leftrightarrow$ AF is limited, although it occurs in the presence acidic catalysts such as polyphosphoric acid [86]. From these lines of evidence, AF and furanic compounds can be produced selectively from the $\mathrm{RE}$ groups of cellulose and its decomposition intermediates. In wood pyrolysis, the LG/AF ratio becomes greater up to 123, because of the action of lignin pyrolysis and the influence of minerals [87]. These components may alter the pyrolysis reactions of REs, although the mechanism details are unknown.

As for the molecular mechanism of the transglycosylation reactions in cellulose pyrolysis, there has been controversy over the mechanisms of homolytic (radical) and heterolytic (ionic) cleavages of the glycosidic bond. The homolysis mechanism has been postulated from the following observations. The depolymerization of cellulose occurs suddenly when the pyrolysis temperature reaches a certain temperature, and the radical species are detected in 
the resulting residue (char). However, concrete experimental evidence is limited for the homolysis mechanism.

Several experimental reports have been reported for the heterolysis mechanism. There is similarity of the decomposition products from cellulose between pyrolysis and acid-catalyzed conditions [88,89]. The research group of Shafizadeh [52,88,90] reported direct evidence for the heterolysis mechanism. They observed that the reactivities of phenyl glucoside derivatives differently substituted at the para-positions increase with the increasing electron attracting property of the substituent. This substituent effect reasonably explains the heterolysis mechanism, because the electron attracting substituent group stabilizes the phenolate anion produced by the heterolytic cleavage of the glycosidic $\mathrm{O}-\mathrm{C}$ bond. They also reported that the 2-deoxy-derivative has a very high reactivity for the pyrolytic cleavage of the glycosidic bond, which is similar to the observation for the acid-catalyzed hydrolysis reaction [52,88,90].

Recently, our research group showed that reducing and non-reducing sugars including LG are substantially stabilized against pyrolytic degradation in some hydrogen bond acceptor solvents such as aromatic substances [91,92] and polyethers $[93,94]$ (see Section 5). These phenomena are not explained by the homolysis mechanism. From theoretical calculations, Hosoya et al. [95] postulated a concerted heterolysis mechanism including the hydrogen bond network (Figure 3). This concerted mechanism prevents the formation of unstable cation/anion complexes, which destabilizes the transition state under pyrolysis conditions because of the lack of solvent stabilization effects [95-98].

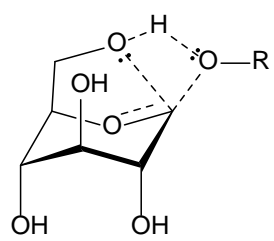

Fig. (3). Concerted heterolysis mechanism proposed for the cleavage of the glycosidic $\mathrm{O}-\mathrm{C}$ bond during pyrolysis [95].

Conformational change from the $\mathrm{C} 1$ to $1 \mathrm{C}$ conformer is noted during the depolymerization of cellulose to LG, because the $\mathrm{C} 1$ conformer, in which all of the substituents bear equatorial positions, is preferable under ambient conditions because of less steric hindrance between 1,3diaxial substituents. Interestingly, this conformational change is possible using the $\mathrm{C}_{1}$ cation for the glucosidic moiety, because the $\mathrm{C}_{1}$ cation is stabilized by the $\mathrm{C}_{6}$ oxygen in the $1 \mathrm{C}$ conformer. As shown by the experimental results for this hypothesis, the anhydropyranose formation from various C6 sugars directly correlates with the relative stability of the $\mathrm{C}_{1}$ cation of the $1 \mathrm{C}$ conformer against that of the corresponding C1 conformer [99].

Several pathways via $1,4-[8,81]$ and 1,2- [100] anhydrosugars as intermediates are postulated for the formation of LG from cellulose, including 1,4:3,6dianhydro- $\alpha$-D-glucopyranose in the cellulose pyrolyzates. However, these pathways have not been established. 1,4:3,6Dianhydro- $\alpha$-D-glucopyranose can be formed via the 3,6- anhydroglucose [101], and 2-O-methyl-cellulose forms 2-Omethyl LG in substantial yields [102]. Recent theoretical calculations [95-98] indicate the direct formation of LG through the attack of the $\mathrm{C}_{6}$-oxygen to $\mathrm{C}_{1}$ in the concerted heterolysis mechanism (Figure 3).

As for the formation of LG from crystalline cellulose, an "unzipping" mechanism has been proposed, in which the continuous production of LG occurs from one end of the cellulose macromolecule following the DP reduction and plateau [16]. However, the formation of anhydrocellooligosaccharides from the fast pyrolysis of cellulose conflicts with the unzipping mechanism. Radlein and Scott [66] proposed the depolymerization mechanism, which releases cellobiosan instead of LG as the primary product, because of the relatively high yield of cellobiosan (6-15 \%) formed from the fast pyrolysis of cellulose. This mechanism is more probable, because cellobiose is the repeating unit of crystalline cellulose. X-ray diffraction analyses indicate that the pyrolytic decomposition of cellulose crystallites occurs heterogeneously [103-105]. Zickler et al. [104] proposed that the pyrolytic decomposition occurs from a direction orthogonal to the cellulose fiber axis as shown by the in situ $\mathrm{X}$-ray diffraction analysis of cellulose pyrolysis.

\subsubsection{Dehydration}

Large amounts of water (14.3 wt\%) form during cellulose pyrolysis in the temperature range of $220-350{ }^{\circ} \mathrm{C}$ [46]. Dehydrated cellulose exhibits characteristic infrared (IR) signals at 1620 and $1735 \mathrm{~cm}^{-1}$, which are assigned to the stretching of the $\mathrm{C}=\mathrm{C}$ and conjugated $\mathrm{C}=\mathrm{O}$ groups, respectively [43,106-108]. The carbonyl structures form via the enol intermediates produced by the dehydration reactions. We reported that the residues obtained during the pyrolysis of cellulose in sulfolane (tetramethylene sulfone) at $330{ }^{\circ} \mathrm{C}$ did not exhibit any such characteristic IR signals, but showed clear birefringence under cross polars (showing crystalline substances) and cellulose I X-ray diffraction patterns [109]. These observations indicate that the dehydration reactions do not proceed in the molecules inside the cellulose crystallites, even at $330{ }^{\circ} \mathrm{C}$.

Direct dehydration from the hydroxyl methylene structures (denoted as Ei elimination) has been suggested [110], but the possibility has not been discussed with experimental results of cellulose and other model substances, and there is a relatively high activation energy (Ea) $(>70$ $\mathrm{kcal} / \mathrm{mol}$ ) obtained by the theoretical calculation [111]. The stability of the model polyalcohols shows that the direct dehydration mechanism is improbable at DTG peak temperatures around $350^{\circ} \mathrm{C}$.

However, dehydration reactions via the reducing sugars have been studied intensively. Monosugars including glucose are not decomposed directly, but via polysaccharide intermediates, whereas the reducing sugars can form continuously through the pyrolytic hydrolysis of cellulose as discussed in Section 3.2.1. The most important finding is the identification of 3-deoxyglycosones, which are formed through the dehydration reactions occurring at the $\mathrm{OH}$ groups at the $\mathrm{C}_{3}$ position of sugars. These compounds are widely discussed as the intermediates regarding the formation of furanic compounds from sugars under acidcatalyzed hydrolysis conditions [112,113]. Kato and Komorita [114] identified 3-deoxyglucosone as a hydrazone 
derivative in the pyrolyzates obtained from glucose and fructose $\left(220^{\circ} \mathrm{C} 10 \mathrm{~min}\right)$ and cellulose $\left(260^{\circ} \mathrm{C} 3 \mathrm{~h}\right)$. These results suggest a dehydration mechanism from glucose to 5HMF as illustrated in Figure 4A. The selective elimination of the $\mathrm{OH}$ group at the $\mathrm{C}_{3}$ position is reasonably explained via the enol intermediate formed by the keto-enol tautomerization (reaction a). The $\beta$-elimination reaction (b) via the six-membered cyclic transition state proceeds effectively to selectively form the 3-deoxy derivative, as indicated by the relatively low Ea (30-40 kcal/mol) calculated theoretically [111,115]. 3-Deoxyglucosone is converted into 5-HMF through the cyclization (d) and the following dehydration (e-h).

A
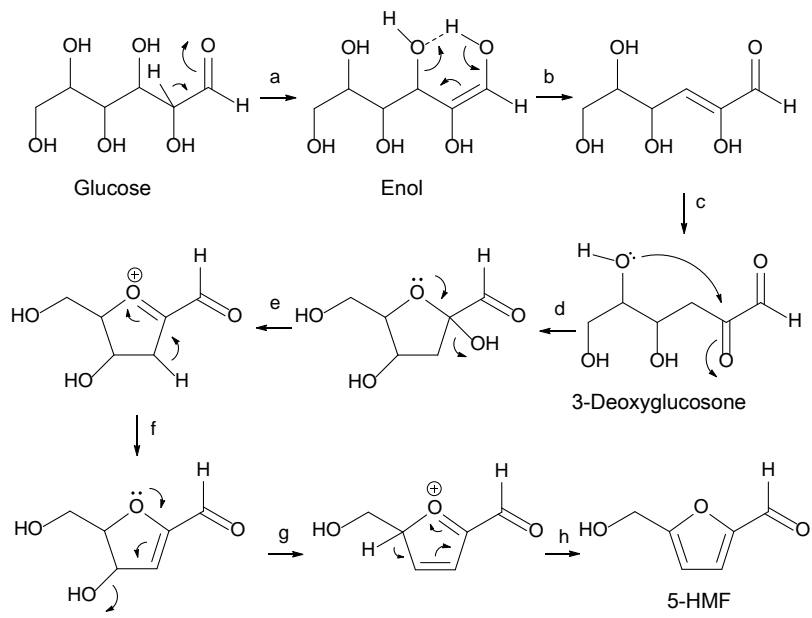

B

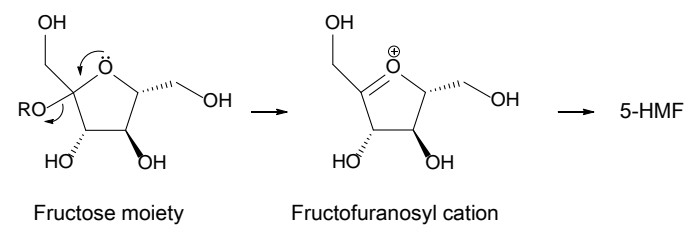

Fig. (4). Dehydration mechanisms proposed for the pyrolytic conversion of (A) glucose and (B) fructose to 5-HMF.

The fructose moiety in sugars is converted into 5-HMF directly from the fructofuranosyl cation, not via 3deoxyglycosone (Figure 4B) [113-118]. A similar pathway can be postulated for glucose after the keto-enol tautomerization into fructose. However, this possibility is refuted by Perez Locas and Yaylayan [118], because the reactivity for the formation of $5-\mathrm{HMF}$ at $300{ }^{\circ} \mathrm{C}$ decreases in the order of fructose $>$ sucrose $>$ 3-deoxyglucosone > glucose.

Investigations with ${ }^{13} \mathrm{C}$-labeled glucose reveal the carbon $\left(\mathrm{C}_{6}\right.$ or $\mathrm{C}_{1}$ ) that is removed during the formation of furfural from glucose. Houminer and Patai [119], Paine et al. [120] and Perez Locas and Yaylayan [118] reported the relative contribution $\left(\mathrm{C}_{6} / \mathrm{C}_{1}\right)$ in this process to be $100 / 0,90 / 10$ and $80 / 20$, respectively. With a similar method, Shafizadeh and Lai [121] reported the contribution $\left(\mathrm{C}_{6} / \mathrm{C}_{1}\right)$ to be $64 / 39$ in the furfural formation from LG pyrolysis. Shafizadeh and Lai [122] also proposed an interesting mechanism for the selective splitting of $C_{6}$ and $C_{1}$ by competitive pathways via 3-deoxyglucosone and 1,4:3,6-dianhydro- $\alpha$-D-glucopyranose, respectively.

The formation mechanism of 1,4:3,6-dianhydro- $\alpha$-Dglucopyranose (3) is not well understood, but several interesting phenomena have been reported. Although the yield of compound $\mathbf{3}$ from the pyrolysis of glucose, cellobiose and cellulose is only up to $1 \%$ [81,122], the yield from 3,6-anhydroglucose can reach $34.8 \%$ [101]. Shafizadeh and Lai [123] reported that 3-deoxyglucosone provides polymerization products in the temperature range of $100-200{ }^{\circ} \mathrm{C}$, which include the 3,6-anhydroglucose moieties. These reported results indicate the possibility that compound $\mathbf{3}$ is formed via 3-deoxyglucosone.

3-Deoxyglucosone is a known intermediate for the formation of 3-deoxyglucuronic acid (glucometasaccharinic acid) in the termination step of the peeling reaction, which proceeds under alkaline conditions. The pyrolytic conversion of 3-deoxyglucosone $\rightarrow$ 3-deoxyglucuronic acid $\rightarrow$ 3deoxyglucuronolactone is confirmed in the literature [124]. The pyrolysis of curdlan, a 1,3-glucan, in the presence of $1.5 \% \mathrm{NaCl}$ gives 3-deoxyglucuronolactone in a high yield of $37 \%$ [125]. Chain depolymerization from the RE is postulated, because the $1 \rightarrow 3$ glucosidic bond is cleaved during a similar reaction as that shown by reaction $\mathrm{b}$ in Figure 4A.

Levoglucosenone (4) [126-128], which has a structure formed by the elimination of two water molecules from LG, is a promising chemical for the preparation of various chiral chemicals that can be utilized for the synthesis of bioactive compounds [129]. The formation of compound $\mathbf{4}$ from cellulose is dramatically accelerated in the presence of acidic additives. Dobele et al. [130] prepared compound $\mathbf{4}$ in a $34 \%$ yield from the pyrolysis of cellulose impregnated with phosphoric acid. In sulfolane, including sulfuric acid or polyphosphoric acid, the yield from cellulose is improved up to $42 \%$ [86]. In this system, water is suggested to be a key factor that promotes the conversion from levoglucosenone to 5-HMF/furfural through the hydrolysis of levoglucosenone into the chain structure, which is required for the pyranose $\rightarrow$ furan ring isomerization. Accordingly, levoglucosenone and 5-HMF/furfural can be prepared selectively by bubbling nitrogen under a mild vacuum condition and steam injection, respectively. Addition of boric acid to this stem inhibits these dehydration reactions by the formation of stable complex with boric acid [131], which also stabilizes cellulose against depolymerization even in the presence of sulfuric acid [132].

$\gamma$-Lactone 5 was reported for the first time in 1988 by Furneaux et al. [133] from the pyrolyzates of cellulose in the presence of Lewis acids. The research group of Fabbri [134136] compared the activities of various catalysts and improved the yield of compound 5 up to $6 \%$.

\subsubsection{Carbonization}

The formation of the benzene rings in cellulose char has been confirmed by the formation of benzenecarboxylic acids using oxidation with permanganate salt, analysis with cross polarization magic angle spinning (CP/MAS) ${ }^{13} \mathrm{C}$ NMR and pyrolysis (Py)-GC/MS. Smith and Howard [137] reported that the polybenzene structures are formed in the char fraction obtained from the slow pyrolysis of cotton linter at the temperatures $>250{ }^{\circ} \mathrm{C}$ because of the formation behavior 
of benzenecarboxylic acids. Shafizadeh and Sekiguchi [138] carefully compared the yields of benzenecarboxylic acids bearing different numbers (1-6) of carboxyl groups from the char fractions prepared at different pyrolysis temperatures. Because the yields of the derivatives with 4-6 carboxyl groups substantially increase at the temperatures between 400 and $500{ }^{\circ} \mathrm{C}$, they concluded that the polyaromatization proceeds in this temperature range.

In 1994, Pastorova et al. [108] reported an important observation to understand the carbonization mechanism of cellulose. They analyzed the char fractions by Py-GC/MS, which were prepared from cellulose at the five different pyrolysis temperatures between 190 and $390{ }^{\circ} \mathrm{C}$. They reported that the composition of the pyrolysis products from char varies significantly depending on the pyrolysis temperature. At $<250{ }^{\circ} \mathrm{C}$, the char fractions provide LG and other products as observed in the pyrolysis of the original cellulose, whereas the composition changes to a mixture of furanoids and benzenoids at $270{ }^{\circ} \mathrm{C}$, and then only benzenoids at $>350{ }^{\circ} \mathrm{C}$. Together with the CP/MAS ${ }^{13} \mathrm{C}$ NMR data, they proposed the conversion mechanism of the carbonized materials from cellulose: pyranose-ring $\rightarrow$ furan ring $\rightarrow$ benzene ring. These observations are interesting, because furanic compounds such as 5-HMF and furfural are expected to form selectively from the RE groups.

Structural change in cellulose carbonization can be observed in the CP/MAS ${ }^{13} \mathrm{C}$ NMR signals in the ranges of 100-160 ppm (aromatic carbons) and 20-80 ppm (aliphatic carbons) [106,108,139,140]. Zhang et al. [141] reported that the conversion from the furan ring to the benzene ring is shown in the CP/MAS ${ }^{13} \mathrm{C}$ NMR spectrum of the aromatic regions of starch-derived char. These spectroscopic features are extensively studied for the carbonization of sugar in hotcompressed water by the research group at the Max Plank Institute [142-144]. Titirici et al. [142] reported that six- and five-carbon sugars are converted in the direction of sixcarbon sugar $\rightarrow$ 5-HMF $\rightarrow$ polyfuran $\rightarrow$ polybenzene and five-carbon sugar $\rightarrow$ furfural $\rightarrow$ polyfuran $\rightarrow$ polybenzene. They also indicated that five-carbon sugars are more easily converted into polybenzene than the six-carbon sugars.

\subsubsection{Fragmentation}

The most important product in this category is hydroxyacetaldehyde (HAA, 8). Hydroxyaldehydes including HAA are easily transformed into dimers and oligomers via the formation of hemiacetals, and forms complex compositions [145]. In the 1980s, a large amount of HAA was reported to be included in the pyrolyzates of cellulose [146,147]. Piskorz et al. [146] and Richards [147] reported the yield of HAA as high as 19 and $9.2 \mathrm{wt} \%$ from the fast pyrolysis and vacuum pyrolysis of cellulose, respectively. Piskorz et al. [64] showed complimentary relationships between the yields of HAA and LG during cellulose pyrolysis. Two competitive pathways were proposed for the formation of HAA and LG [64,148,149]. The pathway forming HAA is preferable at higher temperatures. Julien et al. [150] indicated the role of inorganic contaminants that accelerate the formation of HAA, but reduce the formation of LG from cellulose pyrolysis.

Although the molecular mechanisms have not been studied in detail, the fragmentation pathways have been suggested using ${ }^{13} \mathrm{C}$-labeled cellulose [152], LG [121] and glucose [119,151-157]. Houminer and Patai [119] reported that $\mathrm{CO}$ and $\mathrm{CO}_{2}$ are produced selectively from the $\mathrm{C}_{1}$ of glucose. From the pyrolysis of the polymerization products of glucose labeled with ${ }^{13} \mathrm{C}$ at the $\mathrm{C}_{1}$ or $\mathrm{C}_{3}$ positions, Ponder and Richards [151] reported the origin of formic acid (14; $\left.\mathrm{C}_{1}\right)$, acetic acid $\left(13 ; \mathrm{C}_{5} / \mathrm{C}_{6}\right)$ and HAA $\left(\mathrm{C}_{1} / \mathrm{C}_{2}\right.$ or $\left.\mathrm{C}_{5} / \mathrm{C}_{6}\right)$ from the glucose moiety. These observations are supported by the findings of Paine et al. [156] using the glucose derivatives in which each carbon is separately labeled with ${ }^{13} \mathrm{C}$. They also showed that acetaldehyde tends to include the $\mathrm{C}_{5} / \mathrm{C}_{6}$ of glucose selectively. Furthermore, incorporating ${ }^{13} \mathrm{C}$ into mass spectroscopy fragment ions, the $\mathrm{C}_{4}$ of glucose was reported to be in the aldehyde carbon of acrolein (10), which originates from the $\mathrm{C}_{4} / \mathrm{C}_{5} / \mathrm{C}_{6}$ of glucose [157].

\section{SECONDARY REACTIONS}

The volatile and solid carbonized intermediates formed from the primary pyrolysis of cellulose can undergo secondary reactions in the gas, liquid (following condensation on the reactor wall) and solid phases. The phase, where the pyrolysis intermediates are, affects the secondary reaction pathways significantly. In this section, these features are the focus of discussion.

The desired secondary reaction varies depending on the conversion processes of cellulosic biomass. For bio-oil production through the fast pyrolysis processes, the primary volatiles should be recovered without any secondary reactions. However, drastic conditions, which include higher temperatures and inclusion of the gasifying agents such as $\mathrm{O}_{2}$ and steam, are chosen as gasification processes to maximize the secondary decomposition into gaseous products. Combustion processes need $\mathrm{O}_{2}$ to complete the oxidization of the intermediates into $\mathrm{CO}_{2}$ and $\mathrm{H}_{2} \mathrm{O}$.

\subsection{Boiling Point of Levoglucosan}

LG is an important volatile intermediate from cellulose pyrolysis. Hence, the evaporation process affects the primary pyrolysis and the following secondary reaction stages. Mok and Antal [34] observed an endothermic signal around $220{ }^{\circ} \mathrm{C}$ during the differential thermal analysis of LG under argon flow, because of the evaporation of LG. Milosavljevic et al. [33] estimated the boiling point of LG as around $300{ }^{\circ} \mathrm{C}$, and Feng et al. [158] and Lédé et al. [69] utilized the expected boiling points of 304.5 and $339^{\circ} \mathrm{C}$, respectively, in their papers. The boiling point, $383.38 \pm 42{ }^{\circ} \mathrm{C}$, is listed for LG in SciFinder as a predicted value [159].

The direct measurement is not easy, because LG tends to polymerize at temperatures lower than the boiling point. However, Shoji et al. [32] observed a clear plateau around $385^{\circ} \mathrm{C}$ in the similar experiment to those in Figure 1, except for the utilization of LG instead of cellulose. They concluded that the temperature $385^{\circ} \mathrm{C}$ corresponds to the boiling point of LG, because this technique exhibits plateaus around the temperatures close to the boiling points of other chemicals. Interestingly, the boiling point of LG is slightly higher than the DTG peak temperature of cellulose $\left(350^{\circ} \mathrm{C}\right)$, which indicates that the evaporation process of LG competes with the thermal polymerization occurring at temperatures less than $300{ }^{\circ} \mathrm{C}$. Thus, the relative efficiency of evaporation/polymerization is reported to be a key factor that determines the char yield from the primary pyrolysis of cellulose. Under fast pyrolysis conditions, LG tend to evaporate rather than polymerization $[84,160]$. 


\subsection{Tar and Coke Formation}

The characteristic tar and coke formation of cellulose pyrolysis is illustrated in Figure 5 [161]. These substances are observed mainly on the upper side of the reactor wall at relatively low temperatures, where the volatile intermediates cool and condense into liquid materials. Coke, which is defined as the solid carbonized materials formed via the volatile intermediates, is produced following the condensation process. Polymerization and coking occur following the condensation of the volatile intermediates.

These observations provide insights into the tar/coke formation in the gasification of cellulose and other cellulosic biomasses. Cooling of the gaseous intermediates into liquid substances causes the tar/coke problem on the wall of the pipeline from the outlet of the gasifier. These materials cannot be removed by solvent extraction because of the secondary reactions proceeding after the condensation.

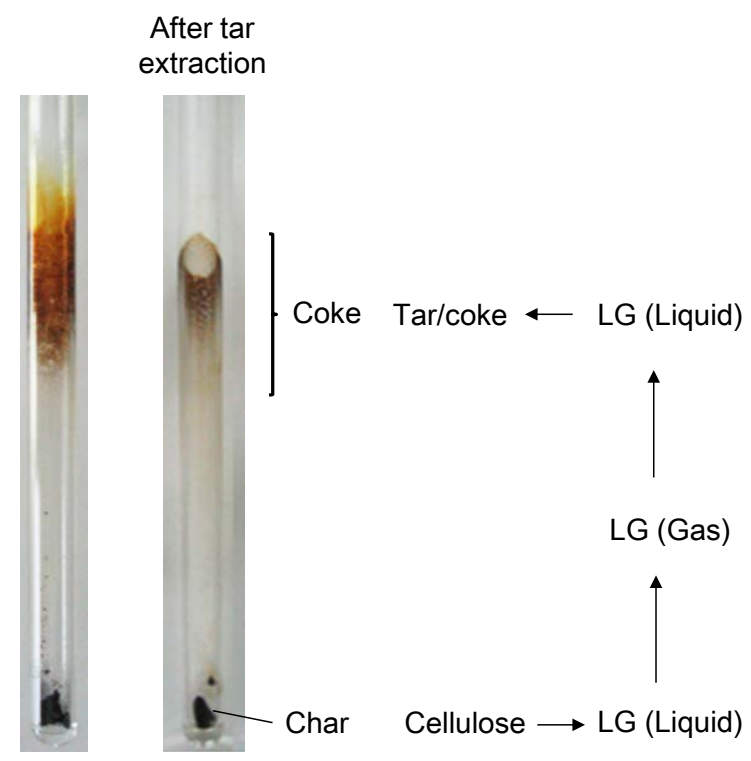

Fig. (5). Tar and coke formation behaviors in cellulose pyrolysis.

Fukutome et al. [62] showed that the yields of LG and AF reach 69.3 and $8.3 \mathrm{wt} \%$, respectively, (total $77.6 \mathrm{wt} \%$ ) from cellulose in the primary pyrolysis stage using a two-stage flow-type experimental setup, which includes pyrolysis and secondary reaction zones. Thus, LG and AF account for a large portion of the volatile materials formed from cellulose. Accordingly, their reactivities in the gas and liquid phases explain the tar and coke forming behaviors observed in Figure 5.

As discussed in Section 3.2.1, neutral salts decrease the yield of anhydromonosugars including LG and enhance char formation. Using $\mathrm{NaCl}, \mathrm{KCl}, \mathrm{MgCl}_{2}$ and $\mathrm{CaCl}_{2}$, the coke formation from cellulose is suppressed, and the amounts of coke coincide with the LG yields [74]. These observations support that the secondary reaction stage of LG after condensation governs coke formation from cellulose.

\subsection{Liquid-phase Reactions}

The liquid-phase reactions of LG have been studied extensively. Pictet [64] indicated the polymerization (transglycosylation) of LG at $240{ }^{\circ} \mathrm{C}$. From the characterization of hydrolysis and Smith degradation (methylation followed by hydrolysis), the polymers were identified as polysaccharides, which include various linkages including $\alpha$ - and $\beta$-anomer types and the anhydrosugar-type terminal units [162-164].

The polymerization of LG is reported to be reversible (LG $\leftrightarrow$ polysaccharides), until the other reactions such as dehydration decompose the glucose moiety in the mixture [165]. The removal of LG through evaporation shifts the reaction to the direction for the formation of LG [165-167]. A mass transfer limitation has been suggested as an important factor that influences the product composition and heat of cellulose pyrolysis. Milosavljevic et al. [33] reported that the heat of cellulose pyrolysis becomes exothermic under conditions where the evaporation of LG is restricted, because of the large exothermicity of the char formation process, which is significantly accelerated under such conditions.

Following polymerization, LG is further degraded into the various products through dehydration and fragmentation as discussed in Section 3.2, which occur at the temperatures lower than the DTG peak temperature $\left(350^{\circ} \mathrm{C}\right)$ of cellulose, because of the amorphous nature of the condensates on the reactor wall (Figure 5). Pyrolysis of wood and other lignocellulosic biomasses mixes volatile products from lignin and hemicellulose in the product stream. Interestingly, the lignin- and xylan-derived products are reported to stabilize LG in the condensates against thermal polymerization (see Section 5) [168].

\subsection{Gas-phase Reactions}

The gas-phase reactions have been studied with a twostage flow-type reactor [169-173]. Antal [169] reported the formation behavior of the gaseous products under steam flow in the temperature range of $500-750{ }^{\circ} \mathrm{C}$. Evans and Milne [170] analyzed the secondary reaction products directly by mass spectroscopy and reported that the primary products are further converted into $\mathrm{CO}$ and $\mathrm{CO}_{2}$ along with alkenes and aromatic substances including furans, benzenes and phenols at temperatures $>700{ }^{\circ} \mathrm{C}$ in a short heating period $(750 \mathrm{~ms})$.

Hosoya et al. [173] reported an interesting observation. The gas-phase pyrolysis of LG does not produce any dehydration products including 5-HMF, furfural and coke, but selectively produces the gaseous products (mainly $\mathrm{CO}$ and $\mathrm{CO}_{2}$ ), from the results using a dual-space ampoule reactor and LG at different loadings. These observations are consistent with the coke formation behavior shown in Figure 5 , in which the coke formation is limited to the reactor wall between the bottom and upper side where large amounts of tar material condense.

This proposal has been confirmed by the gas-phase reactivity of LG, which was studied in the temperature range of $400-900{ }^{\circ} \mathrm{C}$ and a residence time of around $1 \mathrm{~s}$, with a two-stage flow-type reactor including an LG evaporator and a pyrolyzer under nitrogen flow. With careful control of the evaporator temperature, LG evaporates into the gas phase before polymerization and other liquid-phase reactions can start. With this system, Fukutome et al. [174] concluded that LG is stable up to around $500-550{ }^{\circ} \mathrm{C}$, which is different to the pyrolysis in the liquid phase, and selectively fragmented into C1 to C3 aldehydes/ketones/acids at higher temperatures 
$>600{ }^{\circ} \mathrm{C}$. LG completely converted into gaseous products at 800-900 ${ }^{\circ} \mathrm{C}$. Aromatic compounds including furanic compounds and benzenes as well as coke are not produced in the gas-phase pyrolysis of LG. These results strongly indicate that furanic compounds, benzenes and coke originate from the liquid-phase pyrolysis of LG and its decomposition intermediates. Therefore, the gas-phase secondary reactions allow the tar/coke-free clean gasification of cellulose.

This gas-forming reaction via the volatile intermediates from cellulose is an important process in the gasification of wood and other lignocellulosics, because this reactivity is reported to be much greater than those of lignin-derived volatiles, and cellulose- and lignin-derived char intermediates [175]. The major gaseous products from cellulose and LG are $\mathrm{CO}$ and $\mathrm{H}_{2}$ (syngas) along with smaller contributions of $\mathrm{CO}_{2}$ and hydrocarbon gases (methane, ethylene and acetylene). Accordingly, cellulose has a potential as a renewable resource for the production of syngas, which can be utilized for the petroleum synthesis through Fischer-Tropsch reactions. Ethylene, which can be obtained up to the yield of $9 \mathrm{wt} \%$ from cellulose gasification, is also a potential commodity chemical that can substitute that derived from fossil fuels.

High syngas selectivity from cellulose gasification is related to the gas-phase reactions of LG, which gives hydroxyl carbonyl compounds as the intermediates to generate the gaseous products. Fukutome et al. clearly demonstrated that glyceraldehyde (an aldose) and dihydroxyacetone (a ketose) selectively form syngas (CO + $\mathrm{H}_{2}$ ) in the gas phase, from their experimental and theoretical investigations. Because dihydroxyacetone was decomposed via glyceraldehyde though the gas-phase keto-enol tautomerization, a bimolecular mechanism (Ea: 48.7 $\mathrm{kcal} / \mathrm{mol}$ ) was proposed for the gas-phase tautomerization instead of a unimolecular mechanism (Ea: $69.3 \mathrm{kcal} / \mathrm{mol})$. The strong interactions of the hydrogen bond accepting $\mathrm{C}=\mathrm{O}$ group may make the bimolecular reaction probable in the gas phase. These results suggest that the gas-phase pyrolysis of aldose/ketose selectively produces syngas.

As for the molecular mechanism of the gas-phase pyrolysis of LG, Fukutome et al. proposed a mixed mechanism, which includes heterolysis reactions such as cyclic Grob fragmentation and dehydration, and radicalinduced fragmentation, from their kinetic data of the gasphase degradation of LG, along with the reactivities of simple model compounds.

Fukutome et al. also compared the coke and gas formation reactivities for eight major volatile intermediates from cellulose. Furfural, 5-HMF and hydroxyacetone are reported to form coke after their condensation as is observed for LG (Figure 5). Furfural and 5-HMF can form coke continuously from the bottom to the top, which is similar to that behavior of lignin-derived volatiles, and is substantially enhanced in the presence of small amounts of oxygen, whereas the oxygen inhibits gas formation. The gas composition varies depending on the chemical structure of the intermediate. Methyl, carbonyl and carboxyl groups are converted into methane, $\mathrm{CO}$ and $\mathrm{CO}_{2}$ selectively.

\section{HYDROGEN BONDING AS A PRINCIPLE MECHANISM PROMOTING HETEROLYSIS REACTIONS}

There has been a controversy for a long period about the heterolysis and homolysis mechanisms for transglycosylation, dehydration and other reactions discussed in Section 3.2. However, LG is stable in the gas phase as discussed in Section 4.4, and the Ea values of the specific heterolysis from theoretical investigations are too high for these reactions to proceed around the DTG peak temperature of cellulose $\left(350{ }^{\circ} \mathrm{C}\right)$. Bond dissociation energies of the bonds in LG and other carbohydrates are also high. Hosoya et al. [95] proposed a bi-molecular (concerted heterolysis) mechanism from theoretical investigations, which can only explain the transglycosylation proceeding at low pyrolysis temperatures. Several papers have since developed the concerted heterolysis mechanism with theoretical investigations [95-98].

The important role of the bi- and multi-molecular systems in cellulose pyrolysis is indicated experimentally. Hosoya et al. [87] showed that the lignin-derived volatile products stabilize LG against polymerization even after condensing on the reactor wall. They extended this finding to more systematic investigations using simple aromatic compounds [91]. LG, and other simple glycosides were completely stabilized in aromatic compounds up to around $300-350{ }^{\circ} \mathrm{C}$ [91,92]. This stabilizing effect directly relates to the $\pi$ electron density of the aromatic substances, which suggests the $\mathrm{C}-\mathrm{H}---\pi$ and $\mathrm{O}-\mathrm{H}----\pi$ interactions of hydrogen bonding forming between the aromatic substances and LG or simple glycosides. This hydrogen bonding was confirmed by in situ IR measurement of the mixture [92].

From kinetic data, the pyrolytic decomposition of methyl glucoside in an ampoule reactor using diphenyl ether as an aromatic solvent revealed a zero-order reaction [92]. This unexpected result can be explained by the degradation of the methyl glucoside only in the gas phase, because glucoside is completely stabilized by the solvent, which maintains a constant concentration of the gas-phase glucoside during pyrolysis.

Similar stabilization effects are reported for other polyethers such as tetraethyleneglycol dimethyl ether. Matsuoka et al. [93] showed that sugars including glucose are selectively fragmented into HAA and 1,3dihydroxyacetone and their total yield was up to $74.9 \mathrm{wt} \%$ in polyethers. In this system, both polymerization and dehydration products including furfural/5-HMF and char were completely inhibited.

A hydrogen bond theory is proposed, because the reactions, which are inhibited in the hydrogen bond acceptor solvents (aromatics and polyethers), are activated by acidic catalysts [92-94]. As illustrated in Figure 6A, the proton donation through hydrogen bonding may act as an acid catalyst at the temperatures used for pyrolysis. Acid catalysis promotes transglycosylation and dehydration reactions (Figure 6B), and cause the major pyrolytic degradation of 
cellulose and other reducing and non-reducing sugars. However, the base catalysis caused by the association of oxygen (Figure 6A) is less important in the pyrolysis of nonreducing sugars, although this promotes the conversion of reducing sugars from the ring structures to chain structures. The selective fragmentation of the reducing sugars in polyethers can be explained using retro-aldol-type fragmentation via the cyclic transition state (Figure 6C), which is probable even in polyether because of the more basic $\mathrm{C}=\mathrm{O}$ group involved than that of the ether oxygen [93].

A

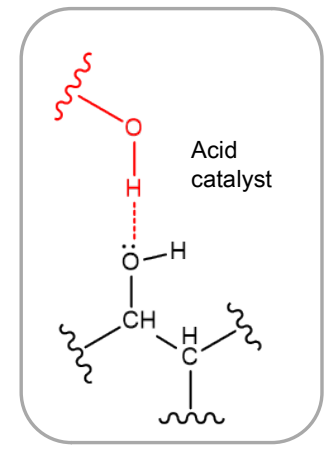

B

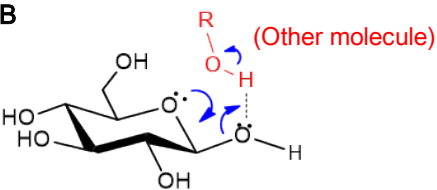

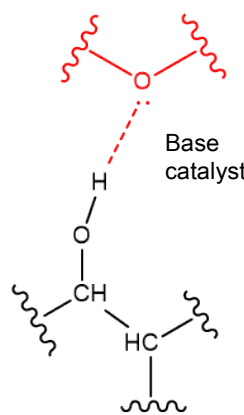

C

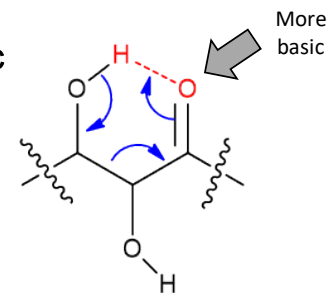

Fig. (6). Hydrogen bond theory acting as acidic and basic catalysts in pyrolysis.

The unexpected stability of the gaseous LG is explained using with this hydrogen bond theory. The bi- and multimolecular reactions are less important in gas-phase pyrolysis, which stabilizes LG and other cellulose-derived intermediates.

\section{ACTIVE CELLULOSE IN THE PYROLYSIS OF CRYSTALLINE CELLULOSE}

The hydrogen bond theory provides insights into the pyrolytic reactivity of cellulose molecules in the crystallites, in which several types of hydrogen bonds are formed $[179,180]$. The cleavage of the $\mathrm{C}_{3}-\mathrm{O} \underline{\mathrm{H}}---\mathrm{O}_{5}$ hydrogen bond and the formation of the hydrogen bond between $\mathrm{C}_{1}$-oxygen (as a hydrogen bond acceptor) and $\mathrm{OH}$ groups of other molecules are required for the effective heterolysis of the glucosidic bond (Figure 7). The $\mathrm{C}_{3}-\mathrm{O} \underline{\mathrm{H}}---\mathrm{O}_{5}$ hydrogen bond increases the stability of the glucosidic bond, because this bond inhibits electron donation to $\mathrm{C}_{1}$. Furthermore, a recent study [181] indicates that the $\mathrm{C}_{3}-\mathrm{O} \underline{\mathrm{H}}---\mathrm{O}_{5}$ hydrogen bond is stable even at $550 \mathrm{~K}\left(277^{\circ} \mathrm{C}\right)$. Due to these specific features, the glucosidic bonds in the crystalline cellulose should be stable against pyrolytic cleavage.

To accomplish the required hydrogen bond pattern, the mobility of the surface cellulose molecules in the crystallite

is important, along with the attack of other molecules from the outside the crystallite. These considerations support the observation that cellulose pyrolysis occurs at the interface of crystallites, not from molecules inside.

Bradbury et al. [182] observed an inductive time before the weight loss of cellulose starts during TGA conducted at temperatures $<300{ }^{\circ} \mathrm{C}$. These findings were used to propose the idea of "active cellulose", which is formed prior to the occurrence of the weight reduction. They also reported that the weight loss behavior of cellulose is explained kinetically by the introduction of the formation process of active cellulose. Such kinetic treatment is described using the Broido-Shafizadeh kinetic model (Figure 8) [8,182,183].

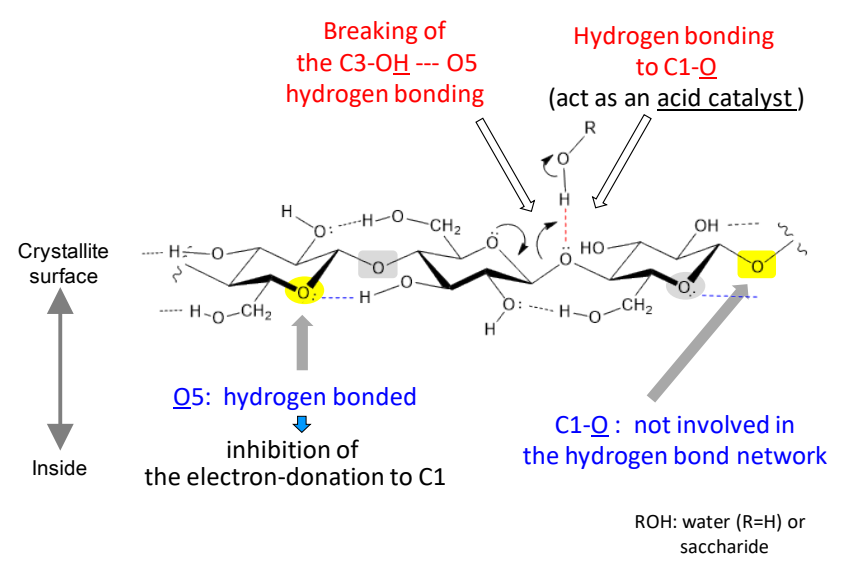

Fig. (7). Hydrogen bond patterns of cellulose molecules in the crystallite, which influences the stability of the glucosidic bond against heterolysis [41].

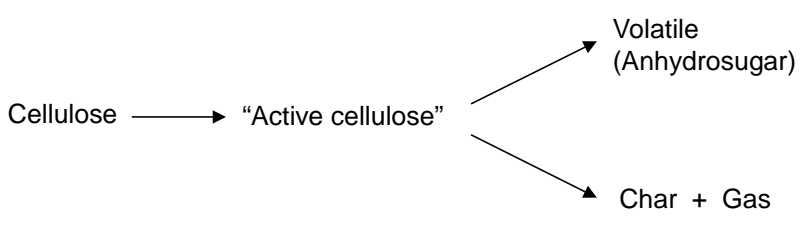

Fig. (8). Broido-Shafizadeh kinetic model.

Liquid intermediates observed during the fast pyrolysis of cellulose have been discussed using active cellulose $[6,30,31]$. However, the temperature range $\left(400-450{ }^{\circ} \mathrm{C}\right)$ where cellulose depolymerization occurs under the fast pyrolysis conditions is higher than the temperatures (< $300{ }^{\circ} \mathrm{C}$ ) where the concept of active cellulose has been proposed. Thus, it is unclear if this liquid intermediate can be directly related to active cellulose.

Matsuoka et al. [41] reported an interesting explanation for active cellulose from the reactivity of cellulose RE groups, which have comparatively high reactivity as discussed in Section 3.1.2. They showed that the induction period, which is the experimental basis for the proposal of active cellulose, is significantly elongated by eliminating the 
REs of cellulose through reduction with $\mathrm{NaBH}_{4}$. This reduction also delays the formation of oligosaccharides and the following weight reduction of cellulose. They proposed the activation mechanism of cellulose during pyrolysis shown in Figure 9.

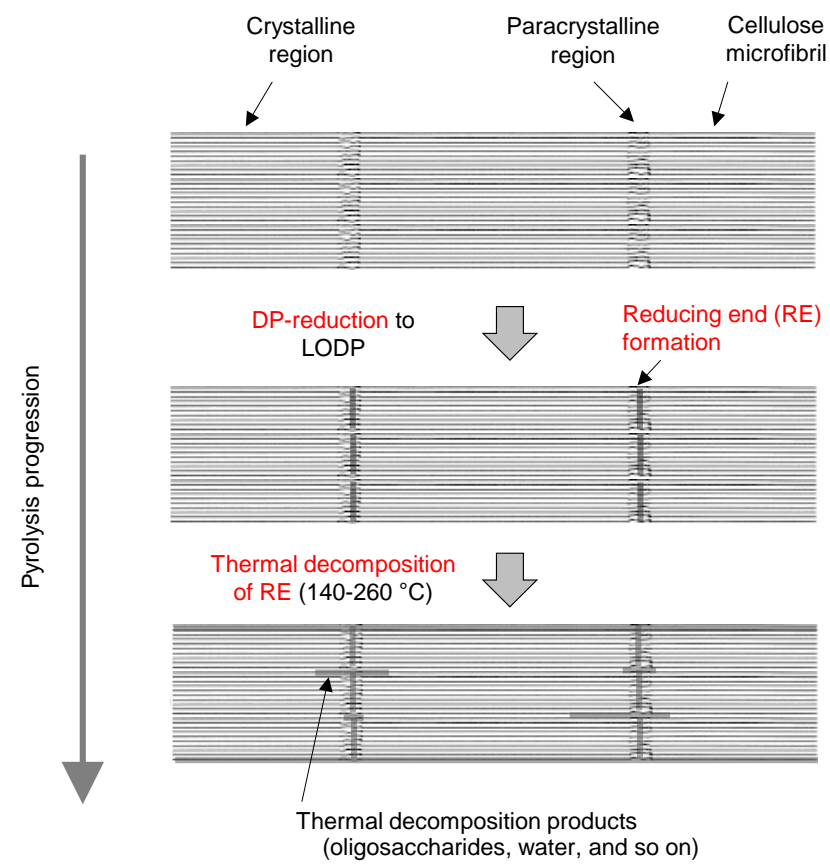

Fig. (9). Proposed activation mechanism of crystalline cellulose [41].

The RE groups, which are already present or newly formed at the ends of the crystallites during the initial DP reduction step, decompose to form water and other products in the temperature range of $140-260{ }^{\circ} \mathrm{C}$. As discussed in Section 3.1.2, the product water may cause hydrolysis of the surface cellulose molecules in the crystallites into oligosaccharides. These processes improve the mobility of the surface molecules of the crystallites. The resulting molten phase of the products including oligosaccharides and water can attack the surface cellulose molecules. These processes may reduce the stability of cellulose against transglycosylation, dehydration and other pyrolysis reactions.

Shoji et al. [32] also explain the decomposition behavior of cellulose under the fast pyrolysis conditions with this activation mechanism, which occurs in the temperature range of $400-450{ }^{\circ} \mathrm{C}$ and converts the molten intermediates into sheet-like char. The activation process in Figure 9 may proceed relatively slowly by adsorbing the heat of evaporation caused from the formation of volatiles. Because of this endothermic process, the pyrolysis temperature stabilizes around $350{ }^{\circ} \mathrm{C}$, even in a furnace at higher temperatures (Figure 1). This activation process may be omitted and replaced by a different mechanism under the very high heating rate, which occurs at $400-450{ }^{\circ} \mathrm{C}$, although the details are unknown presently.

The pyrolytic devolatilization of cellulose has been treated as a first order reaction [3], but some researchers
[184-188] have proposed a nucleation model, in which the decomposition starts locally and spreads over the bulk cellulose. An expected role of the acidic products (acetic acid and formic acid) was postulated for the nucleation model. The activation mechanism illustrated in Figure 9 supports this model.

\section{CONCLUSION}

The heterolysis reactions play important roles in cellulose pyrolysis, whereas most of the lignin pyrolysis reactions occur by homolysis mechanisms. Significant interactions are present in the constituent polymers in the cell walls. These topics are important to understand the molecular mechanisms of the pyrolysis of lignocellulosic biomasses. The heterolysis reactions during cellulose pyrolysis proceed by the catalysis of weak interactions such as hydrogen bonding, which can be controlled easily by changing the pyrolysis environment. These findings provide insights into the advancement of thermochemical conversion technologies of biomass resources.

\section{REFERENCES}

[1] Shafizadeh, F. Introduction to pyrolysis of biomass. J. Anal. Appl. Pyrolysis, 1982, 3 (4), 283-305.

[2] Antal, M. J.: Biomass pyrolysis: A review of the literature part 1 Carbohydrate pyrolysis, “ Advances in Solar Energy”, K. W. Böer, J. A. Duffie eds., American Solar Energy Society Inc., New York, 1982, pp.61-111.

[3] Antal, M. J.; Varhegyi, G. Cellulose pyrolysis kinetics - The current state knowledge. Ind. Eng. Chem. Res., 1995, 34 (3), 703-717.

[4] Antal, M. J.; Grønli, M. The art, science, and technology of charcoal production. Ind. Eng. Chem. Res., 2003, 42 (8), 1619-1640.

[5] Di Blasi, C. Modeling chemical and physical processes of wood and biomass pyrolysis. Prog. Energy Combust. Sci., 2008, 34 (1), 47-90.

[6] Lédé, J. Cellulose pyrolysis kinetics: An historical review on the existence and role of intermediate active cellulose. J. Anal. Appl. Pyrolysis, 2012, 94, 17-32.

[7] Kawamoto, H. Reactions and molecular mechanisms of cellulose pyrolysis, Mokuzai Gakkaishi, 2015, 61(1), 1-24.

[8] Kilzer, F. J.; Broido, A. Speculations on nature of cellulose pyrolysis. Pyrodynamic, 1965, 2 (2-3), 151-163.

[9] Arseneau, D. F. Competitive reactions in thermal decomposition of cellulose. Can. J. Chem., 1971, 49 (4), 632-638.

[10] Lédé, J.; Villermaux, J. Thermal and chemical behavior of solid particles during endothermic decomposition under the effect of external heat-flux. Can. J. Chem. Eng., 1993, 71 (2), 209-217.

[11] Narayan, R.; Antal, M. J. Thermal lag, fusion, and the compensation effect during biomass pyrolysis. Ind. Eng. Chem. Res., 1996, 35 (5), 1711-1721.

[12] Lanzetta, M.; Di Blasi, C.; Buonanno, F. An experimental investigation of heat-transfer limitations in the flash pyrolysis of cellulose. Ind. Eng. Chem. Res., 1997, 36 (3), 542-552.

[13] Antal, M. J.; Varhegyi, G.; Jakab, E. Cellulose pyrolysis kinetics: Revisited. Ind. Eng. Chem. Res., 1998, 37 (4), 1267-1275.

[14] Lin, Y. C.; Cho, J.; Tompsett, G. A.; Westmoreland, P. R.; Huber, G. W. Kinetics and mechanism of cellulose pyrolysis. J. Phys. Chem. C, 2009, 113 (46), 20097-20107.

[15] Chatterjee, P. K.; Conrad, C. M. Thermogravimetric analysis of cellulose. J. Polym. Sci., Part A: Polym. Chem., 1968, 6 (12), 32173233.

[16] Patai, S.; Halper, Y. Pyrolytic reaction of carbohydrates .9. Effect of additives on thermal behavior of cellulose samples of different crystallinity. Isr. J. Chem., 1970, 8 (4), 655-662.

[17] Wang, Z.; Mcdonald, A. G.; Westerhof, R. J. M.; Kersten, S. R. A.; Cuba-Torres, C. M.; Ha, S.; Pecha, B.; Garcia-Perez, M. Effect of cellulose crystallinity on the formation of a liquid intermediate and on product distribution during pyrolysis. J. Anal. Appl. Pyrolysis, 2013, $100,56-66$.

[18] Weinstein, M.; Broido, A. Pyrolysis-crystallinity relationships in cellulose. Combust. Sci. Technol., 1970, 1, 287-292. 
[19] Basch, A.; Lewin, M. Influence of fine-structure on pyrolysis of cellulose .1. Vacuum pyrolysis. J. Polym. Sci., Part A: Polym. Chem., 1973, 11 (12), 3071-3093.

[20] Shimazu, F.; Sterling, C. Effect of wet and dry heat on structure of cellulose. J. Food Sci., 1966, 31 (4), 548-551.

[21] Mcginnis, G. D.; Parikh, S. Thermal-decomposition of methyl $\alpha$-Dglycopyranosides. Carbohydr. Res., 1973, 31 (2), 183-189.

[22] Hengemihle, F. H.; Mcginnis, G. D.; Prince, S.; Templeton, C. Thermal-decomposition of anomeric glycopyranosides. J. Anal. Appl. Pyrolysis, 1984, 6 (3), 317-323.

[23] Kim, U.-J.; Eom, S. H.; Wada, M. Thermal decomposition of native cellulose: Influence on crystallite size. Polym. Degrad. Stab., 2010, 95 (5), 778-781.

[24] Quiévy, N.; Jacquet, N.; Sclavons, M.; Deroanne, C.; Paquot, M., Devaux, J. Influence of homogenization and drying on the thermal stability of microfibrillated cellulose. Polym. Degrad. Stab., 2010, 95 (3), 306-314.

[25] Nordin, S. B.; Nyren, J. O.; Back, E. L. An indication of molten cellulose produced in a laser beam. Text. Res. J., 1974, 44 (2), 152-154.

[26] Schroeter, J.; Felix, F. Melting cellulose. Cellulose, 2005, 12 (2), 159165.

[27] Dauenhauer, P. J.; Colby, J. L.; Balonek, C. M.; Suszynski, W. J.; Schmidt, L. D. Reactive boiling of cellulose for integrated catalysis through an intermediate liquid. Green Chem., 2009, 11 (10), 1555.

[28] Teixeira, A. R.; Mooney, K. G.; Kruger, J. S.; Williams, C. L.; Suszynski, W. J.; Schmidt, L. D.; Schmidt, D. P.; Dauenhauer, P. J. Aerosol generation by reactive boiling ejection of molten cellulose. Energy Environ. Sci., 2011, 4 (10), 4306-4321.

[29] Lédé, J.; Li, H. Z.; Villermaux, J. Fusion-like behavior of wood pyrolysis. J. Anal. Appl. Pyrolysis, 1987, 10 (4), 291-308.

[30] Boutin, O.; Ferrer, M.; Lédé, J. Radiant flash pyrolysis of cellulose evidence for the formation of short life time intermediate liquid species. J. Anal. Appl. Pyrolysis, 1998, 47 (1), 13-31.

[31] Boutin, O.; Ferrer, M.; Lédé, J. Flash pyrolysis of cellulose pellets submitted to a concentrated radiation: Experiments and modelling. Chem. Eng. Sci., 2002, 57 (1), 15-25.

[32] Shoji, T.; Kawamoto, H.; Saka, S. Boiling point of levoglucosan and devolatilization temeratures in cellulose pyrolysis measured at different heating area temperautres. J. Anal. Appl. Pyrolysis, 2014, 109, 185-195.

[33] Milosavljevic, I.; Oja, V.; Suuberg, E. M. Thermal effects in cellulose pyrolysis: Relationship to char formation processes. Ind. Eng. Chem. Res., 1996, 35 (3), 653-662.

[34] Mok, W. S. L.; Antal, M. J. Effects of pressure on biomass pyrolysis .2. Heats of reaction of cellulose pyrolysis. Thermochim. Acta, 1983, 68 (23), $165-186$.

[35] Shafizadeh, F.; Bradbury, A. G. W. Thermal-degradation of cellulose in air and nitrogen at low-temperatures. J. Appl. Polym. Sci., 1979, 23 (5), 1431-1442.

[36] Golova, O. P.; Krylova, R. G. Thermal decomposition of cellulose and its structure. Doklady Akademii Nauk Sssr, 1957, 116 (3), 419-421.

[37] Golova, O. P.; Krylova, R. G. Thermal depolarization of cellulose. Doklady Akademii Nauk Sssr, 1960, 135 (6), 1391-1394.

[38] Halpern, Y.; Patai, S. Pyrolytic reactions of carbohydrates .V. Isothermal decomposition of cellulose in vacuo. Isr. J. Chem., 1969, 7 (5), 673-683.

[39] Broido, A.; Javierson, A. C.; Ouano, A. C.; Barrall, E. M. Molecularweight decrease in early pyrolysis of crystalline and amorphous cellulose. J. Appl. Polym. Sci., 1973, 17 (12), 3627-3635.

[40] Bouchard, J.; Garnier, G.; Vidal, P.; Chornet, E.; Overend, R. P. Characterization of depolymerized cellulosic residues .2. Residues derived from ethylene-glycol solvolysis of cellulose. Wood Sci. Technol., 1990, 24 (2), 159-169.

[41] Matsuoka, S.; Kawamoto, H.; Saka, S. What is active cellulose in pyrolysis? An approach based on reactivity of cellulose reducing end. $J$. Anal. Appl. Pyrolysis, 2014, 106, 138-146.

[42] Matsuoka, S.; Kawamoto, H.; Saka, S. Reducing end-group of cellulose as a reactive site for thermal discoloration. Polym. Degrad. Stab., 2011, 96 (7), 1242-1247.

[43] Tang, M. M.; Bacon, R. Carbonization of cellulose fibers -1 Low temperature pyrolysis. Carbon, 1964, 2, 211-220.

[44] Degroot, W. F.; Pan, W. P.; Rahman, M. D.; Richards, G. N. 1st chemical events in pyrolysis of wood. J. Anal. Appl. Pyrolysis, 1988, 13 (3), 221-231.

[45] Kashiwagi, T.; Nambu, H. Global kinetic constants for thermal oxidative-degradation of a cellulosic paper. Combust. Flame, 1992, 88 (3-4), 345-368.
[46] Scheirs, J.; Camino, G.; Tumiatti, W. Overview of water evolution during the thermal degradation of cellulose. Eur. Polym. J., 2001, 37 (5), 933-942.

[47] Back, E. L.; Htun, M. T.; Jackson, M.; Johanson, F. Ultrasonic measurements of thermal softening of paper products and influence of thermal auto-cross-linking reactions. Tappi, 1967, 50 (11), 542-547.

[48] Matsuoka, S.; Kawamoto, H.; Saka, S. Thermal glycosylation and degradation reactions occurring at the reducing ends of cellulose during low-temperature pyrolysis. Carbohydr. Res., 2011, 346 (2), 272-279.

[49] Tomasik, P.; Palasinski, M.; Wiejak, S. The thermal-decomposition of carbohydrates .1. The decomposition of monosaccharides, disaccharides and oligosaccharides. Adv. Carbohydr. Chem. Biochem., 1989, 47, 203278.

[50] Broido, A.; Houminer, Y.; Patai, S. Pyrolytic reactions of carbohydrates. Part 1. Mutarotation of molten D-glucose. J. Chem. Soc. B: Phys. Org., 1966, 411.

[51] Sugisawa, H.; Usuki, R.; Sasaki, M.; Komura, T. Thermal isomerisation of sugars. Chem. Ind., 1966, (20), 812.

[52] Shafizadeh, F.; Mcginnis, G. D.; Susott, R. A.; Tatton, H. W. Thermal reactions of $\alpha$-D-xylopyranose and $\beta$-D-xylopyranosides. J. Org. Chem., 1971, 36 (19), 2813-2818.

[53] Shafizadeh, F.; Lai, Y. Z. Thermal rearrangements of cellobiose and trehalose. Carbohydr. Res., 1973, 31 (1), 57-67.

[54] Shafizadeh, F.; Lai, Y. Z. Base-catalyzed, pyrolytic rearrangement of some monosaccharides. Carbohydr. Res., 1973, 26 (1), 83-89.

[55] Goring, D. A. I. Thermal softening of lignin, hemicellulose and cellulose. Pulp Paper Mag. Can., 1963, 64, 517-527.

[56] Wada, M. Lateral thermal expansion of cellulose I $\beta$ And III polymorphs. J. Polym. Sci., Part B: Polym. Phys., 2002, 40 (11), 10951102.

[57] Mok, W. S. L.; Antal, M. J.; Szabo, P.; Varhegyi, G.; Zelei, B. Formation of charcoal from biomass in a sealed reactor. Ind. Eng. Chem.Res., 1992, 31 (4), 1162-1166.

[58] Varhegyi, G.; Szabo, P.; Mok, W. S. L.; Antal, M. J. Kinetics of the thermal-decomposition of cellulose in sealed vessels at elevated pressures - effects of the presence of water on the reaction-mechanism. J. Anal. Appl. Pyrolysis, 1993, 26 (3), 159-174.

[59] Yu, Y.; Liu, D.; Wu, H. Characterization of water-soluble intermediates from slow pyrolysis of cellulose at low temperatures. Energy Fuels, 2012, 26 (12), 7331-7339.

[60] Shafizadeh, F.; Furneaux, R. H.; Cochran, T. G.; Scholl, J. P.; Sakai, Y. Production of levoglucosan and glucose from pyrolysis of cellulosic materials. J. Appl. Polym. Sci., 1979, 23 (12), 3525-3539.

[61] Kwon, G. J.; Kim, D. Y.; Kimura, S.; Kuga, S. Rapid-cooling, continuous-feed pyrolyzer for biomass processing. Preparation of levoglucosan from cellulose and starch. J. Anal. Appl. Pyrolysis, 2007, 80 (1), $1-5$.

[62] Fukutome, A.; Kawamoto, H.; Saka, S. unpublished data.

[63] Pictet, A.; Sarasin, J. On the distillation of cellulose and starch under reduced pressure. Helv. Chim. Acta, 1918, 1, 87-96.

[64] Pictet, A. On the tranformation of levoglucoscine to dextrine. Helv. Chim. Acta, 1918, 1, 226-230.

[65] Suzuki, J.; Azuma, J.; Koshijima, T.; Okamura, K.; Okamoto, H. Characterization of monosaccharides and oligosaccharides produced by $\mathrm{CO}_{2}$-laser irradiation on cellulose. Chem. Lett., 1983, (4), 481-484.

[66] Radlein, D. S. G.; Grinshpun, A.; Piskorz, J.; Scott, D. S. On the presence of anhydro-oligosaccharides in the syrups from the fast pyrolysis of cellulose. J. Anal. Appl. Pyrolysis, 1987, 12 (1), 39-49.

[67] Pouwels, A. D.; Eijkel, G. B.; Arisz, P. W.; Boon, J. J. Evidence for oligomers in pyrolysates of microcrystalline cellulose. J. Anal. Appl. Pyrolysis, 1989, 15, 71-84.

[68] Piskorz, J.; Majerski, P.; Radlein, D.; Vladars-Usas, A.; Scott, D. S. Flash pyrolysis of cellulose for production of anhydro-oligomers. $J$. Anal. Appl. Pyrolysis, 2000, 56 (2), 145-166.

[69] Lédé, J.; Blanchard, F.; Boutin, O. Radiant flash pyrolysis of cellulose pellets: Products and mechanisms involved in transient and steady state conditions. Fuel, 2002, 81 (10), 1269-1279.

[70] Hosoya, T.; Kawamoto, H.; Saka, S. Influence of inorganic matter on wood pyrolysis at gasification temperature. J. Wood Sci., 2007, 53 (4), 351-357.

[71] Halpern, Y.; Patai, S. Pyrolytic reactions oc carbohydrates .6. Isothermal decomposition of cellulose in vacuo, in presence of additives. Isr. J. Chem., 1969, 7 (5), 685-690.

[72] Tsuchiya, Y.; Sumi, K. Thermal decomposition products of cellulose. $J$. Appl. Polym. Sci., 1970, 14 (8), 2003-2013. 
[73] Jensen, A.; Dam-Johansen, K.; Wojtowicz, M. A.; Serio, M. A. TGFTIR study of the influence of potassium chloride on wheat straw pyrolysis. Energy Fuels, 1998, 12 (5), 929-938.

[74] Kawamoto, H.; Yamamoto, D.; Saka, S. Influence of neutral inorganic chlorides on primary and secondary char formation from cellulose. $J$. Wood Sci., 2008, 54 (3), 242-246.

[75] Shimada, N.; Kawamoto, H.; Saka, S. Solid-state hydrolysis of cellulose and methyl $\alpha$ - and $\beta$-D-glucopyranosides in presence of magnesium chloride. Carbohydr. Res., 2007, 342 (10), 1373-1377.

[76] Shimada, N.; Kawamoto, H.; Saka, S. Different action of alkali/alkaline earth metal chlorides on cellulose pyrolysis. J. Anal. Appl. Pyrolysis, 2008, 81 (1), 80-87.

[77] Degroot, W. F.; Shafizadeh, F. The influence of exchangeable cations on the carbonization of biomass. J. Anal. Appl. Pyrolysis, 1984, 6 (3), 217-232.

[78] Pan, W. P.; Richards, G. N. Influence of metal-ions on volatile products of pyrolysis of wood. J. Anal. Appl. Pyrolysis, 1989, 16 (2), 117-126.

[79] Richards, G. N.; Zheng, G. C. Influence of metal-ions and of salts on products from pyrolysis of wood - applications to thermochemical processing of newsprint and biomass. J. Anal. Appl. Pyrolysis, 1991, 21 (1-2), 133-146.

[80] Kuzhiyil, N.; Dalluge, D.; Bai, X. L.; Kim, K. H.; Brown, R. C. Pyrolytic sugars from cellulosic biomass. ChemSusChem, 2012, 5 (11), 2228-2236.

[81] Gardiner, D. Pyrolysis of some hexoses and derived di- tri- and polysaccharides. J. Chem. Soc. C-Org., 1966, (17), 1473-1476.

[82] Kato, K. Pyrolysis of cellulose .3. Comparative studies of volatile compounds from pyrolysates of cellulose and its related compounds. Agric. Biol. Chem., 1967, 31 (6), 657-663.

[83] Sanders, E. B.; Goldsmith, A. I.; Seeman, J. I. A model that distinguishes the pyrolysis of D-glucose, D-fructose, and sucrose from that of cellulose. Application to the understanding of cigarette smoke formation. J. Anal. Appl. Pyrolysis, 2003, 66 (1-2), 29-50.

[84] Patwardhan, P. R.; Satrio, J. A.; Brown, R. C.; Shanks, B. H. Product distribution from fast pyrolysis of glucose-based carbohydrates. J. Anal. Appl. Pyrolysis, 2009, 86 (2), 323-330.

[85] Mettler, M. S.; Paulsen, A. D.; Vlachos, D. G.; Dauenhauer, P. J. The chain length effect in pyrolysis: Bridging the gap between glucose and cellulose. Green Chem., 2012, 14 (5), 1284.

[86] Kawamoto, H.; Saito, S.; Hatanaka, W.; Saka, S. Catalytic pyrolysis of cellulose in sulfolane with some acidic catalysts. J. Wood Sci., 2006, 53 (2), 127-133.

[87] Hosoya, T.; Kawamoto, H.; Saka, S. Cellulose-hemicellulose and cellulose-lignin interactions in wood pyrolysis at gasification temperature. J. Anal. Appl. Pyrolysis, 2007, 80 (1), 118-125.

[88] Shafizadeh, F.; Susott, R. A.; Mcginnis, G. D. Pyrolysis of substituted phenyl $\beta$-D-glucopyranosides and 2-deoxy- $\alpha$-D-arabinohexopyranosides. Carbohydr. Res., 1972, 22 (1), 63-73.

[89] Shafizadeh, F.; Mcginnis, G. D.; Philpot, C. W. Thermal-degradation of xylan and related model compounds. Carbohydr. Res., 1972, 25 (1), 2333.

[90] Shafizadeh, F.; Meshreki, M. H.; Susott, R. A. Thermolysis of phenyl glycosides. J. Org. Chem., 1973, 38 (6), 1190-1194.

[91] Hosoya, T.; Kawamoto, H.; Saka, S. Thermal stabilization of levoglucosan in aromatic substances. Carbohydr. Res., 2006, 341 (13), 2293-2297

[92] Kawamoto, H.; Hosoya, T.; Ueno, Y.; Shoji, T.; Saka, S. Thermal stabilization and decomposition of simple glycosides in the presence of aromatic substances in closed ampoules: Role of $\mathrm{OH} \cdot \cdots \pi$ hydrogen bonding. J. Anal. Appl. Pyrolysis, 2014, 109, 41-46.

[93] Matsuoka, S.; Kawamoto, H.; Saka, S. Retro-aldol-type fragmentation of reducing sugars preferentially occurring in polyether at high temperature: Role of the ether oxygen as a base catalyst. J. Anal. Appl. Pyrolysis, 2012, 93, 24-32.

[94] Kawamoto, H.; Ueno, Y.; Saka, S. Thermal reactivities of non-reducing sugars in polyether-role of intermolecular hydrogen bonding in pyrolysis. J. Anal. Appl. Pyrolysis, 2013, 103, 287-292.

[95] Hosoya, T.; Nakao, Y.; Sato, H.; Kawamoto, H.; Sakaki, S. Thermal degradation of methyl $\beta$-D-glucoside. A theoretical study of plausible reaction mechanisms. J. Org. Chem., 2009, 74 (17), 6891-6894.

[96] Seshadri, V.; Westmoreland, P. R. Concerted reactions and mechanism of glucose pyrolysis and implications for cellulose kinetics. J. Phys. Chem. A, 2012, 116 (49), 11997-12013.

[97] Mayes, H. B.; Broadbelt, L. J. Unraveling the reactions that unravel cellulose. J. Phys. Chem. A, 2012, 116 (26), 7098-7106.
[98] Hosoya, T.; Sakaki, S. Levoglucosan formation from crystalline cellulose: Importance of a hydrogen bonding network in the reaction. ChemSusChem, 2013, 6 (12), 2356-2368.

[99] Matsuoka, S.; Kawamoto, H.; Saka, S. Influence of hydroxyl group configuration on pyrolytic formation of 1,6-anhydrohexopyranoses from various hexoses: An experimental and theoretical study. J. Anal. Appl. Pyrolysis, 2013, 103, 300-306.

[100] Byrne, G. A.; Gardiner, D.; Holmes, F. H. Pyrolysis of cellulose and action of flame-retardants .2. Further analysis and identification of products. J. Appl. Chem., 1966, 16 (3), 81-88.

[101] Bedford, G. R.; Gardiner, D. The two 1,4;3,6-dianhydro-Dhexopyranoses. Chem. Commun., 1965, (13), 287-288.

[102] Wollwage, P. C.; Seib, P. A. Thermal degradation of 2-Omethylcellulose. Carbohydr. Res., 1969, 10 (4), 589-594.

[103] Kim, D. Y.; Nishiyama, Y.; Wada, M.; Kuga, S.; Okano, T. Thermal decomposition of cellulose crystallites in wood. Holzforschung, 2001, 55 (5), 521-524.

[104] Zickler, G. A.; Wagermaier, W.; Funari, S. S.; Burghammer, M.; Paris, O. In situ X-ray diffraction investigation of thermal decomposition of wood cellulose. J. Anal. Appl. Pyrolysis, 2007, 80 (1), 134-140.

[105] Kawamoto, H.; Saka, S. Heterogeneity in cellulose pyrolysis indicated from the pyrolysis in sulfolane. J. Anal. Appl. Pyrolysis, 2006, 76 (1-2), 280-284.

[106] Sekiguchi, Y.; Frye, J. S.; Shafizadeh, F. Structure and formation of cellulosic chars. J. Appl. Polym. Sci., 1983, 28 (11), 3513-3525.

[107] Julien, S.; Chornet, E.; Tiwari, P. K.; Overend, R. P. Vacuum pyrolysis of cellulose - fourier-transform infrared characterization of solid residues, product distribution and correlations. J. Anal. Appl. Pyrolysis, 1991, 19, 81-104.

[108] Pastorova, I.; Botto, R. E.; Arisz, P. W.; Boon, J. J. Cellulose char structure - A combined analytical PY-GC-MS, FTIR, and NMR-study. Carbohydr. Res., 1994, 262 (1), 27-47.

[109] Kawamoto, H.; Hatanaka, W.; Saka, S. Thermochemical conversion of cellulose in polar solvent (sulfolane) into levoglucosan and other low molecular-weight substances. J. Anal. Appl. Pyrolysis, 2003, 70 (2), 303-313.

[110] Boon, J. J.; Pastorova, I.; Botto, R. E.; Arisz, P. W. Structural studies on cellulose pyrolysis and cellulose chars by PY MS, PY GC MS, FTIR, NMR and by wet chemical techniques. Biomass Bioenergy, 1994, 7 (16), 25-32.

[111] Nimlos, M. R.; Blanksby, S. J.; Quian, X., Himmel, M. E., Johnson, D. K. Mechanism of glycerol dehydration. J. Phys. Chem. A, 2006, 110, 6145-6156.

[112] Anet, E. 3-Deoxyhexosones. J. Am. Chem. Soc., 1960, 82 (6), 15021502.

[113] Van Putten, R. J.; Van Der Waal, J. C.; De Jong, E.; Rasrendra, C. B.; Heeres, H. J.; De Vries, J. G. Hydroxymethylfurfural, a versatile platform chemical made from renewable resources. Chem. Rev., 2013, 113 (3), 1499-1597.

[114] Van Putten, R. J.; Van Der Waal, J. C.; De Jong, E.; Rasrendra, C. B.; Heeres, H. J.; De Vries, J. G. Hydroxymethylfurfural, a versatile platform chemical made from renewable resources. Chem. Rev., 2013, 113 (3), 1499-1597.

[115] Fukutome, A; Kawamoto, H; Saka, S. Gas-phase reactions of glyceraldehyde and 1,3-dihydroxyacetone as models for levoglucosan conversion during biomass gasification. ChemSusChem, in press (DOI: 10.1002/cssc.201501612).

[116] Antal, M. J.; Mok, W. S.; Richards, G. N. Mechanism of formation of 5-(hydroxymethyl)-2-furaldehyde from D-fructose an sucrose. Carbohydr. Res., 1990, 199 (1), 91-109.

[117] Kuster, B. F. M. 5-Hydroxymethylfurfural (HMF) - A review focusing on its manufacture. Starch-Starke, 1990, 42 (8), 314-321.

[118] Locas, C. P.; Yaylayan, V. A. Isotope labeling studies on the formation of 5-(hydroxymethyl)-2-furaldehyde (HMF) from sucrose by pyrolysis-GC/MS. J. Agric. Food. Chem., 2008, 56 (15), 6717-6723.

[119] Houminer, Y.; Patai, S. Thermal decomposition of D-glucose labelled with ${ }^{14} \mathrm{C}$ at various positions. Tetrahedron Lett., 1967, (14), 1297-1300.

[120] Paine, J. B.; Pithawalla, Y. B.; Naworal, J. D. Carbohydrate pyrolysis mechanisms from isotopic labeling part 4. The pyrolysis of D-glucose: The formation of furans. J. Anal. Appl. Pyrolysis, 2008, 83 (1), 37-63.

[121] Shafizadeh, F.; Lai, Y. Z. Thermal-degradation of 1,6-anhydro- $\beta$-Dglucopyranose. J. Org. Chem., 1972, 37 (2), 278-284.

[122] Shafizadeh, F.; Furneaux, R. H.; Stevenson, T. T.; Cochran, T. G. Acid-catalyzed pyrolytic synthesis and decomposition of 1,4;3,6dianhydro- $\alpha$-D-glucopyranose. Carbohydr. Res., 1978, 61, 519-528. 
[123] Shafizadeh, F.; Lai, Y. Z. Thermal-degradation of 3-deoxy-D-erythrohexosulose. Carbohydr. Res., 1975, 40 (2), 263-274.

[124] Shafizadeh, F.; Lai, Y. Z. Thermal-degradation of 2-deoxy-D-arabinohexonic acid and 3-deoxy-D-ribo-hexono-1,4-lactone. Carbohydr. Res., 1975, 42 (1), 39-53.

[125] Richards, G. N.; Shafizadeh, F. Formation of glucometasaccharinolactones in the pyrolysis of curdlan, a $(1 \rightarrow 3)-\beta-D-$ glucan. Carbohydr. Res., 1982, 106 (1), 83-91).

[126] Halpern, Y.; Riffer, R.; Broido, A. Levoglucosenone (1,6-anhydro3,4-dideoxy- $\Delta^{3}-\beta$-D-pyranosen-2-one) - A major product of acidcatalyzed pyrolysis of cellulose and related carbohydrates. J. Org. Chem., 1973, 38 (2), 204-209.

[127] Broido, A.; Evett, M.; Hodges, C. C. Yield of 1,6-anhydro-3,4dideoxy- $\beta$-D-glycero-hex-3-enopyranos-2-ulose (levoglucosenone) on acid-catalyzed pyrolysis of cellulose and 1,6-anhydro- $\beta$-Dglucopyranose (levoglucosan). Carbohydr. Res., 1975, 44 (2), 267-274.

[128] Shafizadeh, F.; Chin, P. P. S. Preparation of 1,6-anhydro-3,4-dideoxy$\beta$-D-glycero-hex-3-enopyranos-2-ulose (levoglucosenone) and some derivatives thereof. Carbohydr. Res., 1977, 58 (1), 79-87.

[129] Isobe, M.; Yamamoto, N.; Nishikawa, T. Levoglucosenone as chiral pool for synthesis. "Levoglucosenone and levogllucosan", Witczak, Z. J. ed., ATL press, Inc., Mount Prospect, USA, 1994, pp. 99-118.

[130] Dobele, G.; Dizhbite, T.; Rossinskaja, G.; Telysheva, G.; Meier, D.; Radtke, S.; Faix, O. Pre-treatment of biomass with phosphoric acid prior to fast pyrolysis. J. Anal. Appl. Pyrolysis, 2003, 68-69, 197-211.

[131] Kawamoto, H.; Saito, S.; Saka, S. Stable complex formation with boric acid in pyrolysis of levoglucosan in acidic media. J. Anal. Appl. Pyrolysis, 2008, 82 (1), 78-82.

[132] Kawamoto, H.; Saito, S.; Saka, S. Inhibition of acid-catalyzed depolymerization of cellulose with boric acid in non-aqueous acidic media. Carbohydr. Res., 2008, 343 (2), 249-255

[133] Furneaux, R. H.; Mason, J. M.; Miller, I. J. A novel hydroxylactone from the lewis acid catalysed pyrolysis of cellulose. J. Chem. Soc., Perkin Trans. 1, 1988, (1), 49-51.

[134] Traetteberg, M.; Bakken, P.; Hopf, H.; Mlynek, C.; Mahle, A. H. Intramolecular $\mathrm{OH} / \mathrm{pi}$ interaction: The molecular structure and conformations of 3-hexyn-1,6-diol. J. Mol. Struct., 2000, 554 (2-3), 191-202.

[135] Fabbri, D.; Torri, C.; Baravelli, V. Effect of zeolites and nanopowder metal oxides on the distribution of chiral anhydrosugars evolved from pyrolysis of cellulose: An analytical study. J. Anal. Appl. Pyrolysis, 2007, 80 (1), 24-29.

[136] Fabbri, D.; Torri, C.; Mancini, I. Pyrolysis of cellulose catalysed by nanopowder metal oxides: Production and characterisation of a chiral hydroxylactone and its role as building block. Green Chem., 2007, 9 (12), 1374.

[137] Smith, R. C.; Howard, H. C. Aromatization of cellulose by heat. J. Am. Chem. Soc., 1937, 59, 234-236.

[138] Shafizadeh, F.; Sekiguchi, Y. Development of aromaticity in cellulosic chars. Carbon, 1983, 21 (5), 511-516.

[139] Sekiguchi, Y.; Shafizadeh, F. The effect of inorganic additives on the formation, composition, and combustion of cellulosic char. J. Appl. Polym. Sci., 1984, 29 (4), 1267-1286.

[140] Soares, S.; Ricardo, N.; Jones, S.; Heatley, F. High temperature thermal degradation of cellulose in air studied using FTIR and ${ }^{1} \mathrm{H}$ and ${ }^{13} \mathrm{C}$ solid-state NMR. Eur. Polym. J., 2001, 37 (4), 737-745.

[141] Zhang, X. Q.; Golding, J.; Burgar, I. Thermal decomposition chemistry of starch studied by ${ }^{13} \mathrm{C}$ high-resolution solid-state NMR spectroscopy. Polymer, 2002, 43 (22), 5791-5796.

[142] Titirici, M. M.; Antonietti, M.; Baccile, N. Hydrothermal carbon from biomass: A comparison of the local structure from poly- to monosaccharides and pentoses/hexoses. Green Chem., 2008, 10 (11), 1204-1212.

[143] Baccile, N.; Laurent, G.; Babonneau, F.; Fayon, F.; Titirici, M. M.; Antonietti, M. Structural characterization of hydrothermal carbon spheres by advanced solid-state MAS ${ }^{13} \mathrm{C}$ NMR investigations. J. Phys. Chem. C, 2009, 113 (22), 9644-9654.

[144] Falco, C.; Caballero, F. P.; Babonneau, F.; Gervais, C.; Laurent, G.; Titirici, M. M.; Baccile, N. Hydrothermal carbon from biomass: Structural differences between hydrothermal and pyrolyzed carbons via ${ }^{13} \mathrm{C}$ solid state NMR. Langmuir, 2011, 27 (23), 14460-14471.

[145] Hosoya, T.; Kawamoto, H.; Saka, S. Oxime-trimethylsilylation method for analysis of wood pyrolysate. J. Anal. Appl. Pyrolysis, 2006, 77 (2), 121-126.

[146] Piskorz, J.; Radlein, D.; Scott, D. S. On the mechanism of the rapid pyrolysis of cellulose. J. Anal. Appl. Pyrolysis, 1986, 9 (2), 121-137.
[147] Richards, G. N. Glycolaldehyde from pyrolysis of cellulose. J. Anal. Appl. Pyrolysis, 1987, 10 (3), 251-255.

[148] Banyasz, J. L.; Li, S.; Lyons-Hart, J. L.; Shafer, K. H. Cellulose pyrolysis: The kinetics of hydroxyacetaldehyde evolution. J. Anal. Appl. Pyrolysis, 2001, 57 (2), 223-248.

[149] Luo, Z. Y.; Wang, S. R.; Liao, Y. F.; Cen, K. F. Mechanism study of cellulose rapid pyrolysis. Ind. Eng. Chem. Res., 2004, 43 (18), 56055610.

[150] Julien, S.; Chornet, E.; Overend, R. P. Influence of acid pretreatment $\left(\mathrm{H}_{2} \mathrm{SO}_{4}, \mathrm{HCl}, \mathrm{HNO}_{3}\right)$ on reaction selectivity in the vacuum pyrolysis of cellulose. J. Anal. Appl. Pyrolysis, 1993, 27 (1), 25-43.

[151] Ponder, G. R.; Richards, G. N. Mechanisms of pyrolysis of polysaccharides .7. Pyrolysis of some ${ }^{13} \mathrm{C}$-labeled glucans - A mechanistic study. Carbohydr. Res., 1993, 244 (1), 27-47.

[152] Evans, R. J.; Wang, D. N.; Agblevor, F. A.; Chum, H. L.; Baldwin, S. D. Mass spectrometric studies of the thermal decomposition of carbohydrates using ${ }^{13} \mathrm{C}$-labeled cellulose and glucose. Carbohydr. Res., 1996, 281 (2), 219-235.

[153] Houminer, Y.; Patai, S. Pyrolytic reactions of carbohydrates .2. Thermal decomposition of D-glucose. Isr. J. Chem., 1969, 7 (4), 513524.

[154] Houminer, Y.; Hoz, S.; Patai, S. Pyrolytic reactions of carbohydrates .8. Decomposition of D-glucose labelled with ${ }^{14} \mathrm{C}$ at different positions, catalyzed by various additives. Isr. J. Chem., 1969, 7 (6), 821-825.

[155] Houminer, Y.; Hoz, S. Formation of formaldehyde in thermal decomposition of D-glucose labelled with ${ }^{14} \mathrm{C}$ at various positions. Isr. J. Chem., 1970, 8 (1), 97-98.

[156] Paine, J. B.; Pithawalla, Y. B.; Naworal, J. D. Carbohydrate pyrolysis mechanisms from isotopic labeling part 2. The pyrolysis of D-glucose: General disconnective analysis and the formation of C1 and C2 carbonyl compounds by electrocyclic fragmentation mechanisms. $J$. Anal. Appl. Pyrolysis, 2008, 82 (1), 10-41.

[157] Paine, J. B.; Pithawalla, Y. B.; Naworal, J. D. Carbohydrate pyrolysis mechanisms from isotopic labeling part 3 . The pyrolysis of D-glucose: Formation of C3 and C4 carbonyl compounds and a cyclopentenedione isomer by electrocyclic fragmentation mechanisms. J. Anal. Appl. Pyrolysis, 2008, 82 (1), 42-69.

[158] Feng, W.; Van Der Kooi, H. J.; Arons, J. D. Application of the SAFT equation of state to biomass fast pyrolysis liquid. Chem. Eng. Sci., 2005, 60 (3), 617-624.

[159] Scifinder, Chemical Abstracts Service: Columbus, OH; https://scifinder.cas.org (accessed September 16, 2014); calculated using Advanced Chemistry Devepolement (ACD/Labs) Software V11.02.1994-2013.

[160] Mettler, M. S.; Paulsen, A. D.; Vlachos, D. G.; Dauenhauer, P. J. Pyrolytic conversion of cellulose to fuels: Levoglucosan deoxygenation via elimination and cyclization within molten biomass. Energy Environ. Sci., 2012, 5 (7), 7864.

[161] Hosoya, T.; Kawamoto, H.; Saka, S.; Pyrolysis behaviors of wood and its constituent polymers at gasification temperature. J. Anal. Appl. Pyrolysis, 2007, 78 (2), 328-336.

[162] Shafizadeh, F.; Fu, Y. L. Pyrolysis of cellulose. Carbohydr. Res., 1973, 29 (1), 113-122.

[163] Wolfrom, M. L.; Thompson, A.; Ward, R. B. The composition of pyrodextrins 2. Thermal polymerization of levoglucosan. J. Am. Chem. Soc., 1959, 81 (17), 4623-4625.

[164] Wolfrom, M. L.; Ward, R. B.; Horton, D.; Moore, R. H.; Thompson, A. Composition of pyrodextrins 3 . Thermal polymerization of levoglucosan. J. Org. Chem., 1961, 26 (11), 4617-1620.

[165] Kawamoto, H.; Murayama, M.; Saka, S. Pyrolysis behavior of levoglucosan as an intermediate in cellulose pyrolysis: Polymerization into polysaccharide as a key reaction to carbonized product formation. $J$. Wood Sci., 2003, 49 (5), 469-473.

[166] Bai, X.; Johnston, P.; Brown, R. C. An experimental study of the competing processes of evaporation and polymerization of levoglucosan in cellulose pyrolysis. J. Anal. Appl. Pyrolysis, 2013, 99, 130-136.

[167] Bai, X.; Johnston, P.; Sadula, S.; Brown, R. C. Role of levoglucosan physiochemistry in cellulose pyrolysis. J. Anal. Appl. Pyrolysis, 2013, 99, 58-65.

[168] Kawamoto, H.; Morisaki, H.; Saka, S. Secondary decomposition of levoglucosan in pyrolytic production from cellulosic biomass. J. Anal. Appl. Pyrolysis, 2009, 85 (1-2), 247-251. 
[169] Antal, M. J. Effects of reactor severity on the gas-phase pyrolysis of celulose-derived and kraft lignin-derived volatile matter. Ind. Eng. Chem. Prod. Res. Dev., 1983, 22 (2), 366-375.

[170] Evans, R. J.; Milne, T. A. Molecular characterization of the pyrolysis of biomass .1. Fundamentals. Energy Fuels, 1987, 1 (2), 123-137.

[171] Li, S.; Lyons-Hart, J.; Banyasz, J.; Shafer, K.; Real-time evolved gas analysis by FTIR method: An experimental study of cellulose pyrolysis. Fuel, 2001, 80 (12), 1809-1817.

[172] Shin, E. J.; Nimlos, M. R.; Evans, R. J. Kinetic analysis of the gasphase pyrolysis of carbohydrates. Fuel, 2001, 80 (12), 1697-1709.

[173] Hosoya, T.; Kawamoto, H.; Saka, S. Different pyrolytic pathways of levoglucosan in vapor- and liquid/solid-phases. J. Anal. Appl. Pyrolysis, 2008, 83 (1), 64-70.

[174] Fukutome, A; Kawamoto, H; Saka, S. Processes forming gas, tar, and coke in cellulose gasification from gas-phase reactions of levoglucosan as intermediate. ChemSusChem, 2015, 8, 2240-2249.

[175] Hosoya, T.; Kawamoto, H.; Saka, S. Pyrolysis gasification reactivities of primary tar and char fractions from cellulose and lignin as studied with a closed ampoule reactor. J. Anal. Appl. Pyrolysis, 2008, 83 (1), 71-77.

[176] Fukutome, A; Kawamoto, H; Saka, S. Gas-phase reactions of glyceraldehyde and 1,3-dihydroxyacetone as models for levoglucosan conversion during biomass gasification. ChemSusChem, in press (DOI: 10.1002/cssc.201501612).

[177] Fukutome, A.; Kawamoto, H.; Saka, S. unpublished data.

[178] Fukutome, A.; Kawamoto, H.; Saka, S. Gas- and coke-forming reactivities of cellulose-derived tar components under nitrogen and oxygen/nitrogen. J. Anal. Appl. Pyrolysis, 2014, 108, 98-108.
[179] Nishiyama, Y.; Langan, P.; Chanzy, H. Crystal structure and hydrogen-bonding system in cellulose $1 \beta$ from synchrotron X-ray and neutron fiber diffraction. J. Am. Chem. Soc., 2002, 124 (31), 9074-9082.

[180] Nishiyama, Y.; Sugiyama, J.; Chanzy, H.; Langan, P. Crystal structure and hydrogen bonding system in cellulose $1 \alpha$, from synchrotron X-ray and neutron fiber diffraction. J. Am. Chem. Soc., 2003, 125 (47), 1430014306.

[181] Agarwal, V.; Huber, G. W.; Conner, W. C., Jr.; Auerbach, S. M. Simulating infrared spectra and hydrogen bonding in cellulose $1 \beta$ at elevated temperatures. J. Chem. Phys., 2011, 135 (13), 134506.

[182] Bradbury, A. G. W.; Sakai, Y.; Shafizadeh, F. Kinetic-model for pyrolysis of cellulose. J. Appl. Polym. Sci., 1979, 23 (11), 3271-3280.

[183] Broido, A.; Nelson, M. A. Char yield on pyrolysis of cellulose. Combust. Flame, 1975, 24 (2), 263-268.

[184] Dollimor, D.; Holt, B. Thermal-degradation of cellulose in nitrogen. $J$. Polym. Sci., Part B: Polym. Phys., 1973, 11 (9), 1703-1711.

[185] Reynolds, J. G.; Burnham, A. K. Pyrolysis decomposition kinetics of cellulose-based materials by constant heating rate micropyrolysis. Energy Fuels, 1997, 11 (1), 88-97.

[186] Capart, R.; Khezami, L.; Burnham, A. K. Assessment of various kinetic models for the pyrolysis of a microgranular cellulose. Thermochim. Acta, 2004, 417 (1), 79-89.

[187] Mamleev, V.; Bourbigot, S.; Yvon, J. Kinetic analysis of the thermal decomposition of cellulose: The main step of mass loss. J. Anal. Appl. Pyrolysis, 2007, 80 (1), 151-165.

[188] Mamleev, V.; Bourbigot, S.; Le Bras, M.; Yvon, J. The facts and hypotheses relating to the phenomenological model of cellulose pyrolysis. J. Anal. Appl. Pyrolysis, 2009, 84 (1), 1-17. 


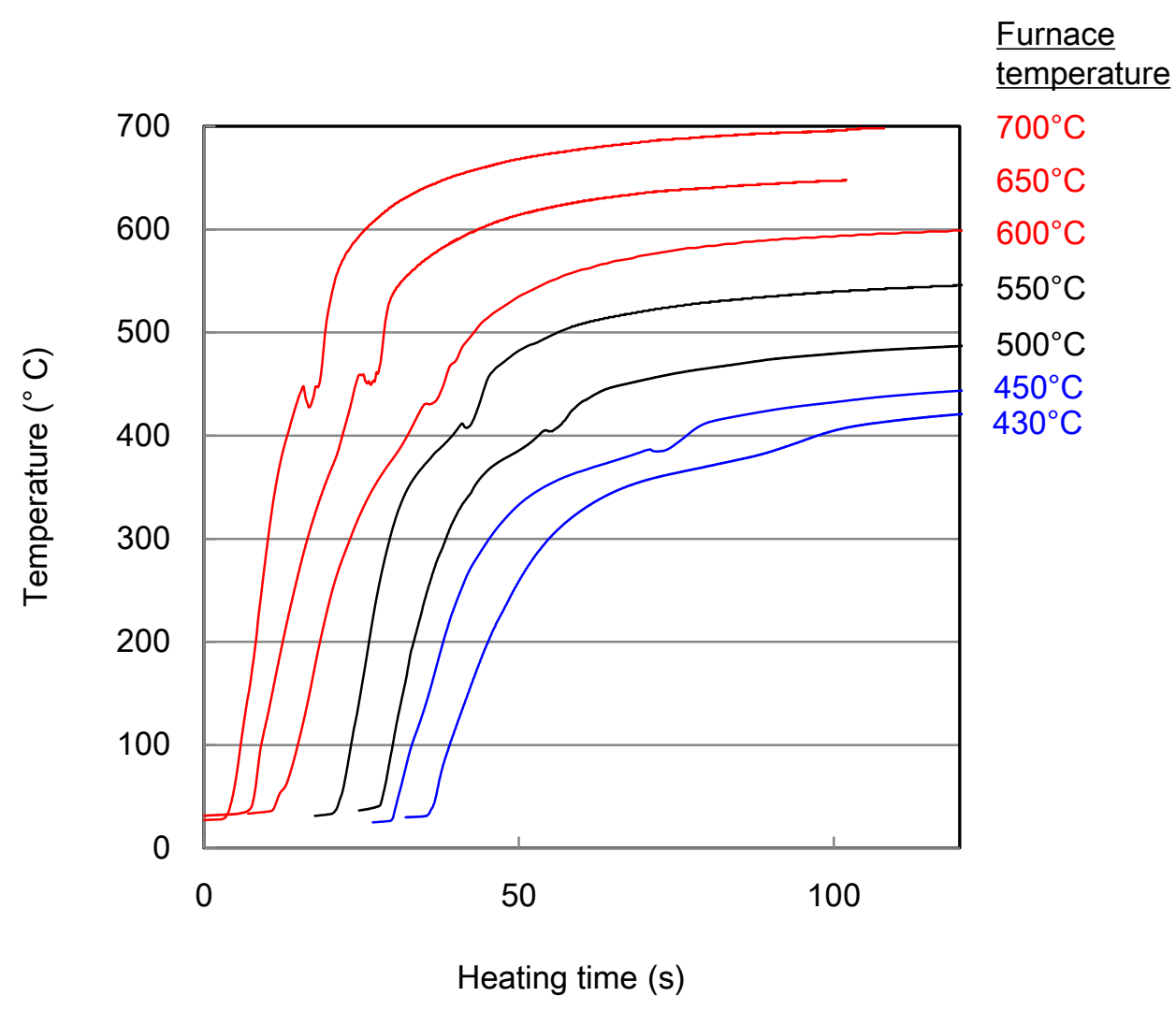

Fig. 1 


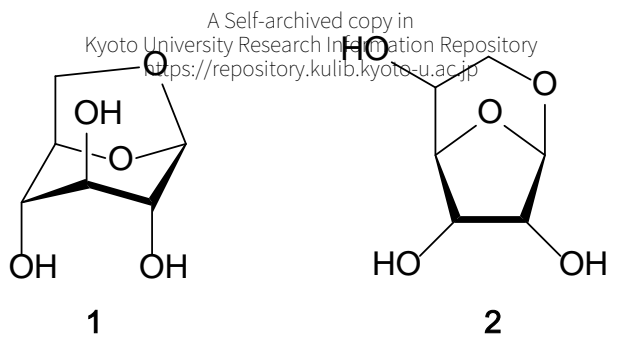

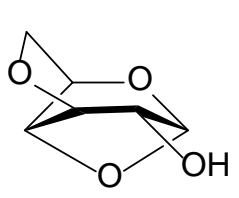

3

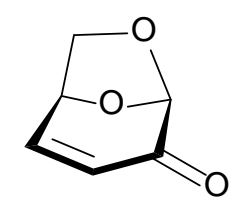

4

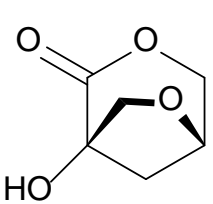

5

\section{Dehydration}
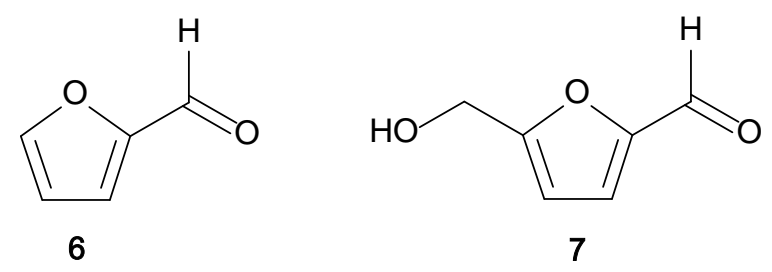

Fragmentation

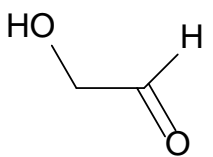

8

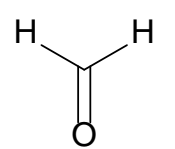

9

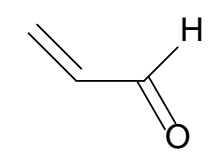

10

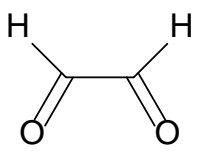

11

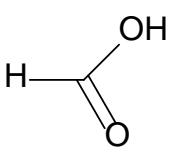

14

Fig. 2 


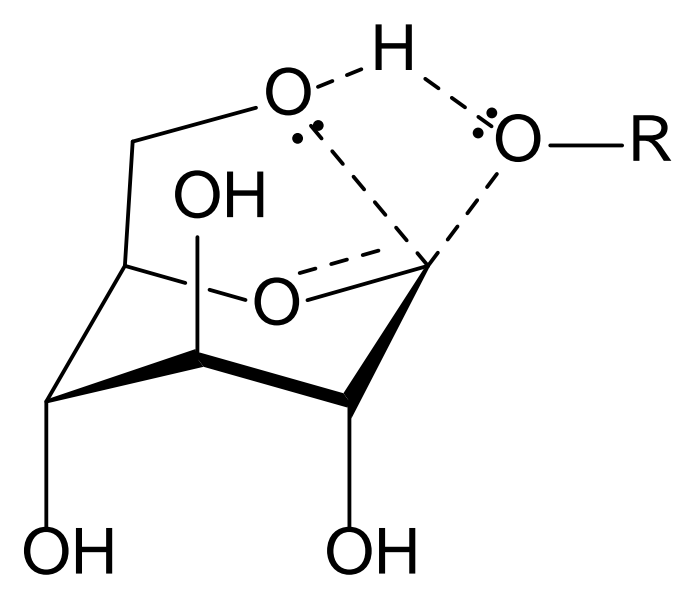

Fig. 3 


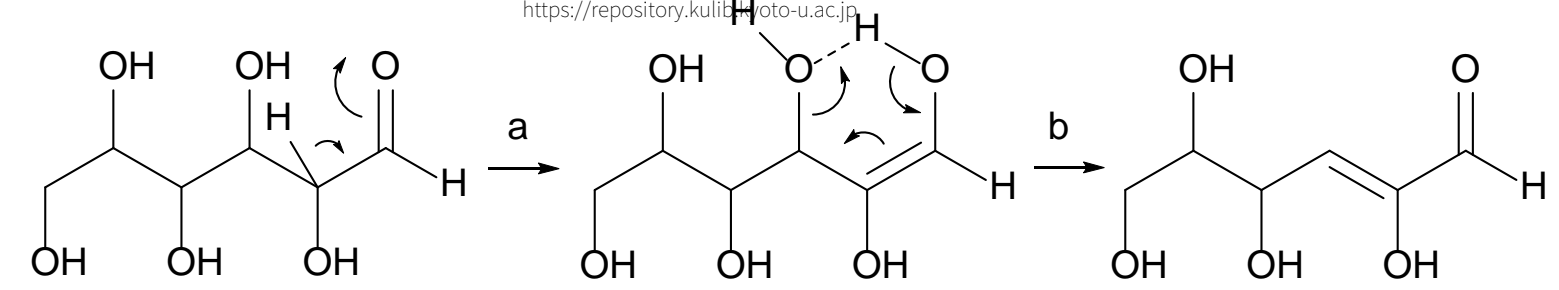

Glucose

Enol<smiles>CC(C)C(O)C(CO)[OH+]CCCC(=O)C=O</smiles><smiles>O=Cc1ccc(CO)o1</smiles>

B<smiles>[R6]C1(CO)O[C@H](CO)[C@@H](O)[C@H]1O</smiles><smiles>OCC1=[O+][C@@H](CO)[C@@H](O)[C@@H]1O</smiles>

Fructose moiety

Fructofuranosyl cation

Fig. 4 


\section{After tar \\ extraction}
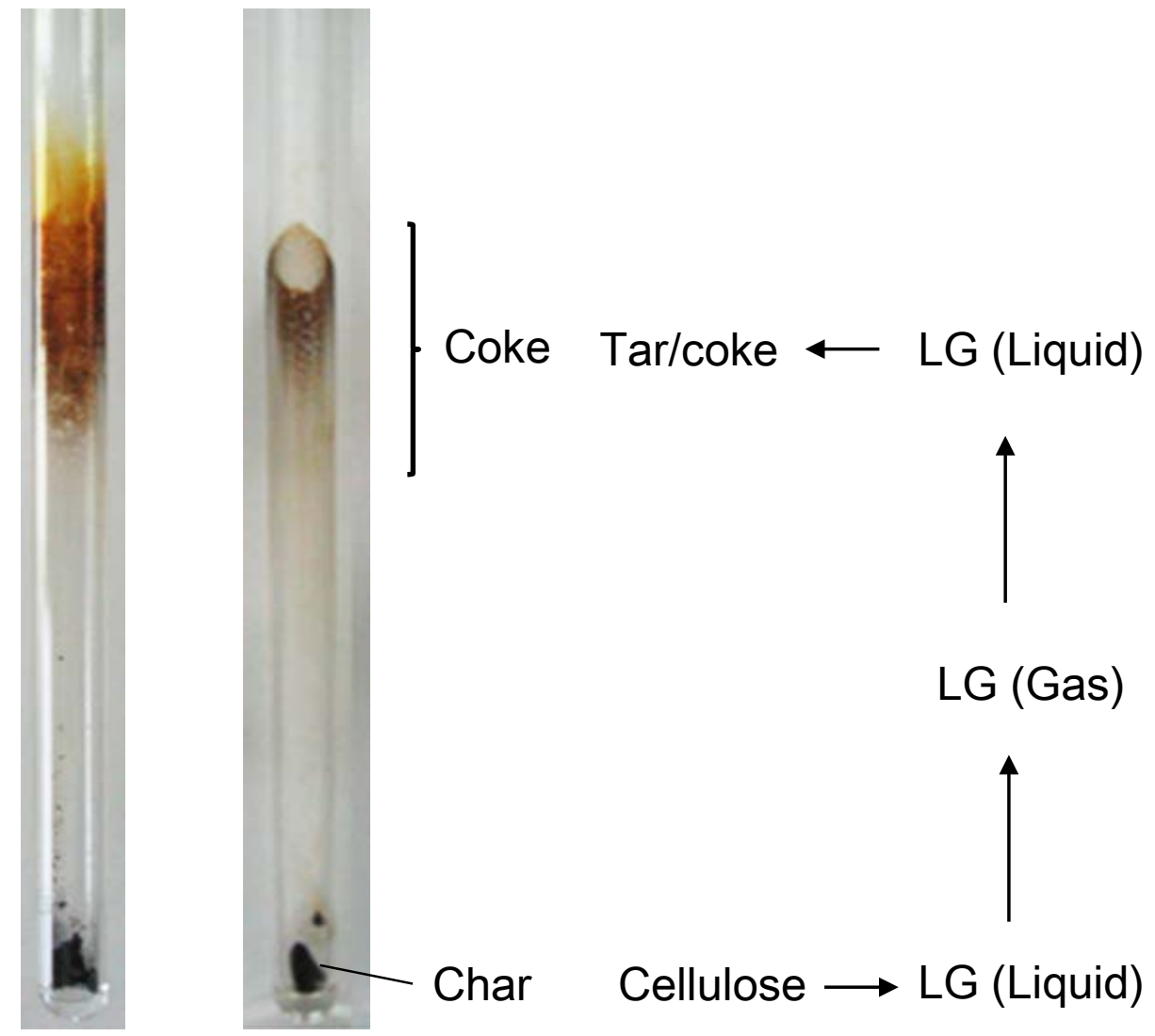

Fig. 5 

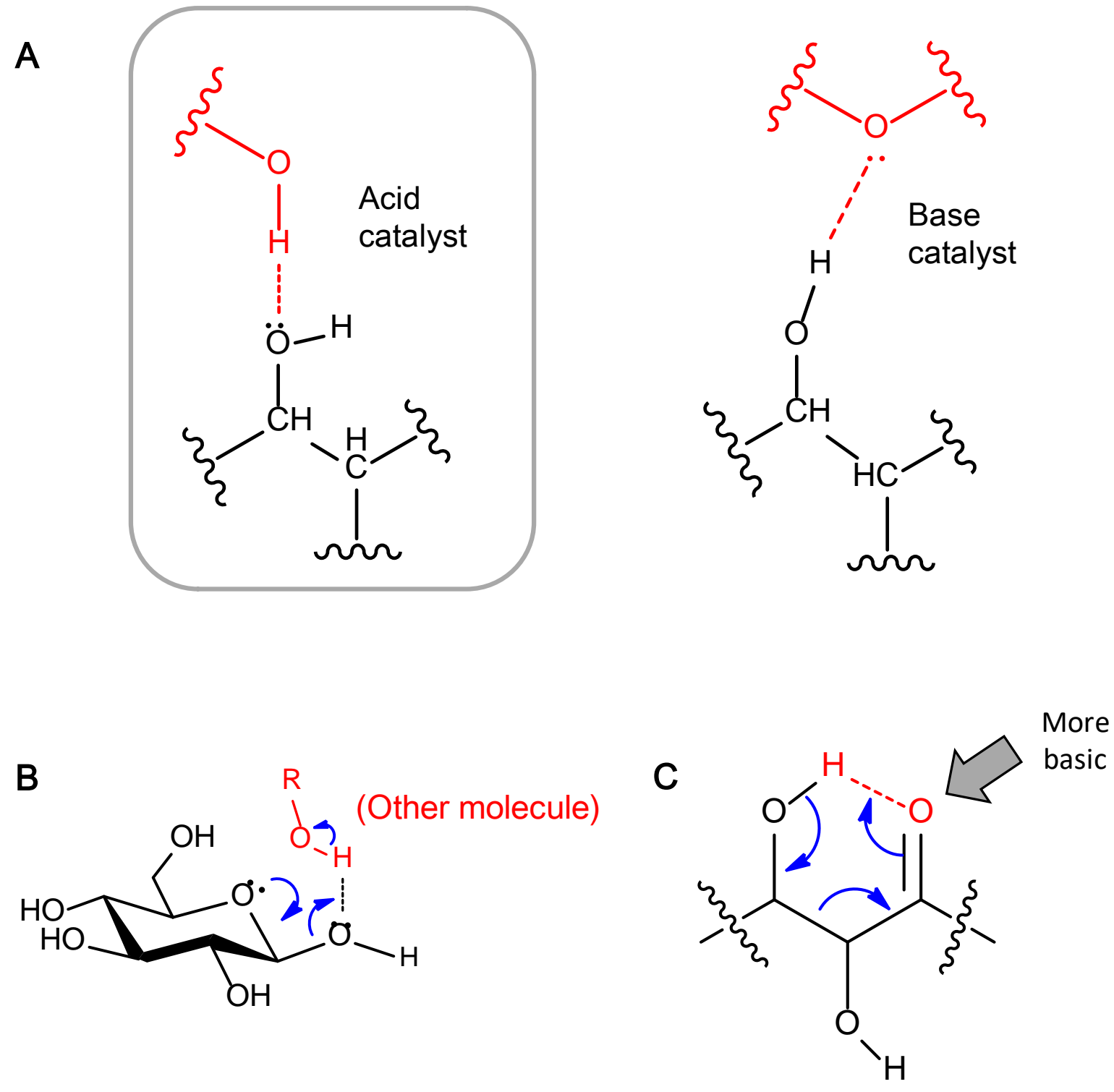

Fig. 6 


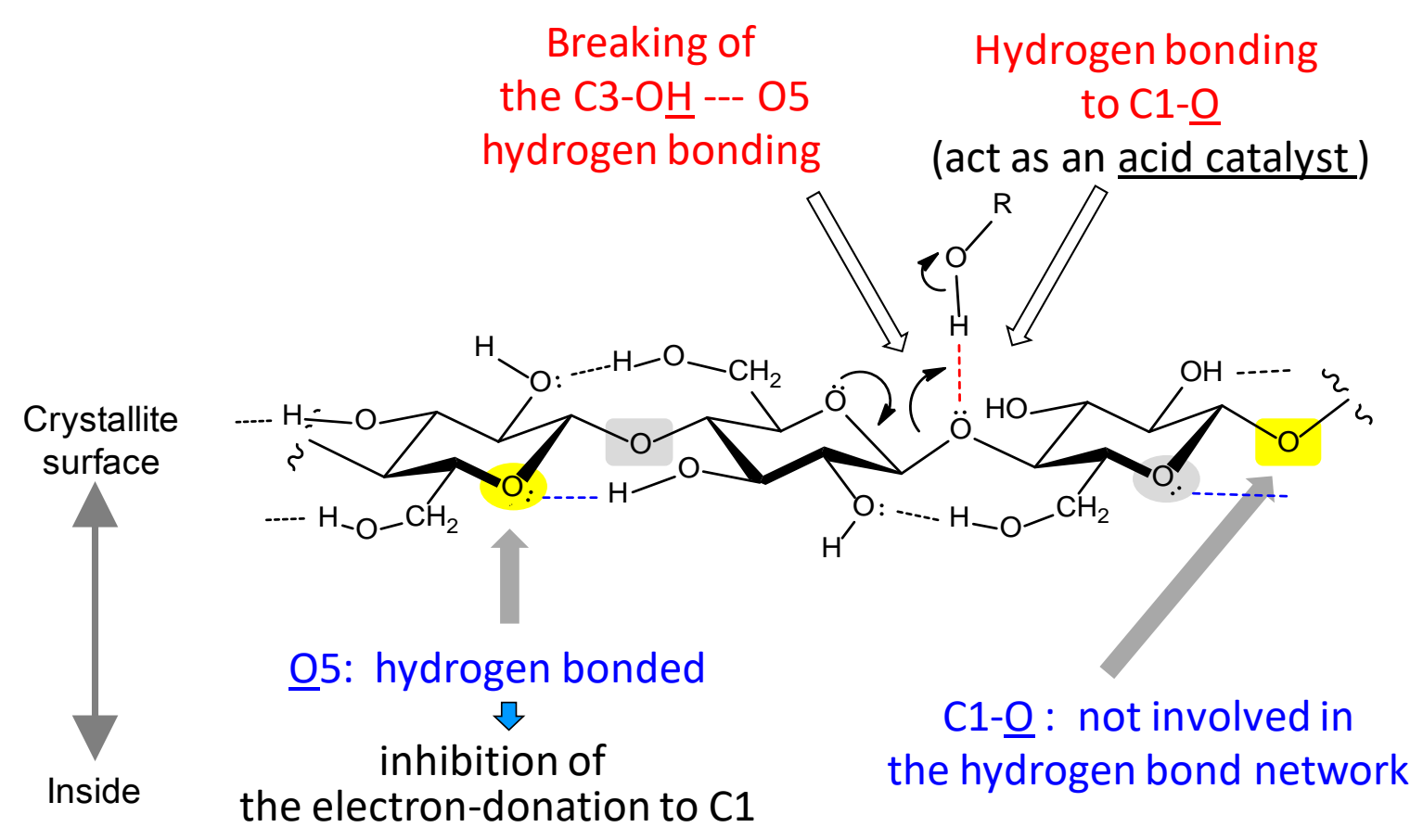

$\mathrm{ROH}$ : water $(\mathrm{R}=\mathrm{H})$ or saccharide

Fig. 7 


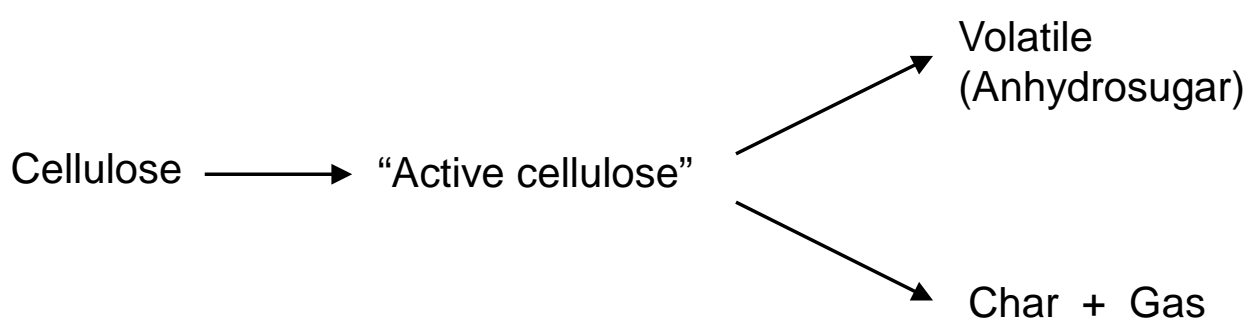

Fig. 8 


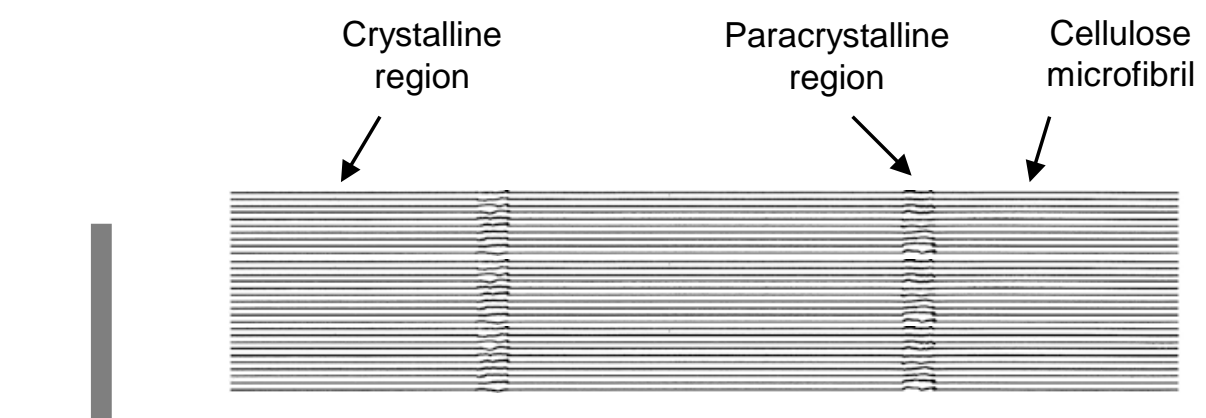

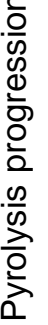

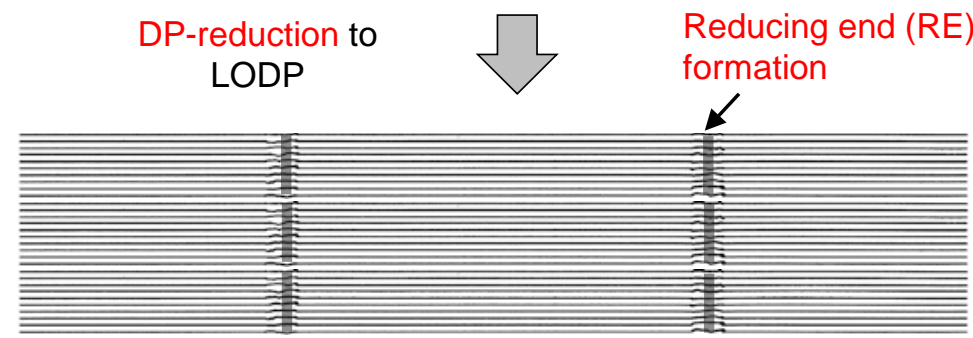

Thermal decomposition of RE $\left(140-260^{\circ} \mathrm{C}\right)$

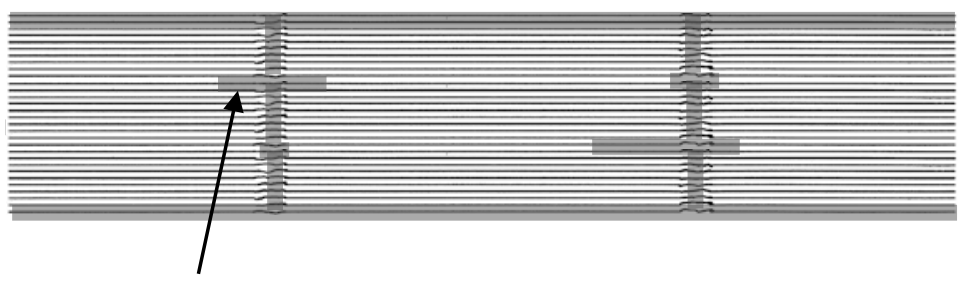

Thermal decomposition products

(oligosaccharides, water, and so on)

Fig. 9 